\title{
Global Epidemiology of Plasmodium vivax
}

\author{
Rosalind E. Howes, ${ }^{1,2} \dagger$ Katherine E. Battle, ${ }^{1}+\dagger$ Kamini N. Mendis, ${ }^{3}$ David L. Smith, $, 5,6$ Richard E. Cibulskis, ${ }^{3}$ \\ J. Kevin Baird, ${ }^{7,8}$ and Simon I. Hay ${ }^{4,6,9 *}$ \\ ${ }^{1}$ Spatial Ecology and Epidemiology Group, Department of Zoology, University of Oxford, Oxford, United Kingdom; ${ }^{2}$ Center for Global Health \\ and Diseases, Case Western Reserve University, Cleveland, Ohio, ${ }^{3}$ Global Malaria Program, World Health Organization, Geneva, Switzerland; \\ ${ }^{4}$ Fogarty International Center, National Institutes of Health, Bethesda, Maryland; ${ }^{5}$ Sanaria Institute for Global Health and Tropical Medicine, \\ Rockville, Maryland; ${ }^{6}$ Institute for Health Metrics and Evaluation, University of Washington, Seattle, Washington; ${ }^{7}$ Eijkman-Oxford \\ Clinical Research Unit, Jakarta, Indonesia; ${ }^{8}$ Centre for Tropical Medicine and Global Health, Nuffield Department of Medicine, \\ University of Oxford, Oxford, United Kingdom; ${ }^{9}$ Wellcome Trust Centre for Human Genetics, University of Oxford, \\ Roosevelt Drive, Oxford, United Kingdom
}

\begin{abstract}
Plasmodium vivax is the most widespread human malaria, putting 2.5 billion people at risk of infection. Its unique biological and epidemiological characteristics pose challenges to control strategies that have been principally targeted against Plasmodium falciparum. Unlike $P$. falciparum, $P$. vivax infections have typically low blood-stage parasitemia with gametocytes emerging before illness manifests, and dormant liver stages causing relapses. These traits affect both its geographic distribution and transmission patterns. Asymptomatic infections, high-risk groups, and resulting case burdens are described in this review. Despite relatively low prevalence measurements and parasitemia levels, along with high proportions of asymptomatic cases, this parasite is not benign. Plasmodium vivax can be associated with severe and even fatal illness. Spreading resistance to chloroquine against the acute attack, and the operational inadequacy of primaquine against the multiple attacks of relapse, exacerbates the risk of poor outcomes among the tens of millions suffering from infection each year. Without strategies accounting for these $P$. vivax-specific characteristics, progress toward elimination of endemic malaria transmission will be substantially impeded.
\end{abstract}

\section{INTRODUCTION}

Plasmodium vivax and Plasmodium falciparum are the primary causes of malaria in humans and until recent years, the majority of malaria research and funding has been focused on the prevention, treatment, and control of $P$. falciparum. ${ }^{1}$ Both parasite species expose approximately 2.5 billion people to risk of infection. ${ }^{2,3}$ Although $P$. falciparum causes many deaths, especially in sub-Saharan Africa where $P$. vivax is rarer, the predominance of $P$. vivax in some of the world's most densely populated and impoverished regions, coupled with its now proven association with severe and fatal outcomes, informs the importance of reversing the historic neglect of this infection. A deeper understanding of the unique epidemiology of this parasite is necessary for effective malaria control and elimination efforts. A synthesis of the current status of this knowledge represents this review's objective.

Important variances in the biology of $P$. vivax and $P$. falciparum render their epidemiologies distinctly different. The most apparent is the ability of $P$. vivax to cause relapses weeks to months following a primary infection by activation

* Address correspondence to Katherine E. Battle, Big Data Institute, Nuffield Department of Medicine, University of Oxford, c/o Wellcome Trust Centre for Human Genetics, Roosevelt Drive, Oxford OX3 7BN, United Kingdom, E-mail: katherine.battle@well .ox.ac.uk or Simon I. Hay, Institute for Health Metrics and Evaluation, University of Washington, 2301 5th Ave, Suite 600, Seattle, WA 98121, E-mail: sihay@uw.edu.

$\dagger$ These authors contributed equally to this work.

(c) World Health Organization 2016. Licensee American Journal of Tropical Medicine and Hygiene. This is an open access article distributed under the terms of the Creative Commons Attribution IGO License (http://creativecommons.org/licenses/by/3.0/igo/legalcode), which permits unrestricted use, distribution, and reproduction in any medium, provided the original work is properly cited. In any reproduction of this article there should not be any suggestion that WHO or this article endorse any specific organization or products. The use of the WHO logo is not permitted. This notice should be preserved along with the article's original URL. of dormant liver-stage parasites, known as hypnozoites. These dormant liver-stage infections constitute what is called the hypnozoite reservoir of infection. That reservoir streams new blood infections and clinical attacks into these communities, along with opportunities for onward transmission. The hypnozoite reservoir extends clinical attacks across seasons inhospitable to anopheline mosquitoes, effectively widening its natural geographic range far into temperate zones including the Korean Peninsula. ${ }^{2}$

There also exist differences in the blood-stage dynamics that impact $P$. vivax epidemiology. Natural immunity is acquired at a younger age than against $P$. falciparum, making infants the primary risk group for severe vivax malaria in heavily endemic settings. ${ }^{4}$ In low-transmission settings, where $P$. vivax often persists against elimination efforts, all age groups appear at risk of severe disease. ${ }^{4}$ The propensity for $P$. vivax to invade young blood cells (reticulocytes) and its ability to migrate beyond the venous sinuses results in relatively low levels of parasitemia. ${ }^{5}$ Even in low-transmission settings, most infections appear to be microscopically sub-patent and asymptomatic. ${ }^{4}$

Low blood-stage parasitemia does not make $P$. vivax a "benign" infection, as once believed. ${ }^{5-7}$ Despite low levels of detectable parasites, $P$. vivax causes significant morbidity and can be associated with severe malaria and death. ${ }^{5,8-20}$ Remarkably, the primary therapies against such outcomes, chloroquine and primaquine, have been in continuous use since 1952, despite worsening resistance to chloroquine and the operational inadequacy of primaquine where most malaria patients live and seek treatment.

This article reviews the epidemiology of $P$. vivax in the context of these crucial issues. The geographic distribution of $P$. vivax infection and differences in relapse phenotype are illustrated and described alongside estimates of $P$. vivax burden, as well as severe, lethal, and chloroquine-resistant vivax malaria to demonstrate that control and elimination strategies developed for $P$. falciparum cannot simply be transferred to P. vivax. ${ }^{21-25}$ The problems imposed by the unique biology of $P$. vivax require the development and implementation of a 


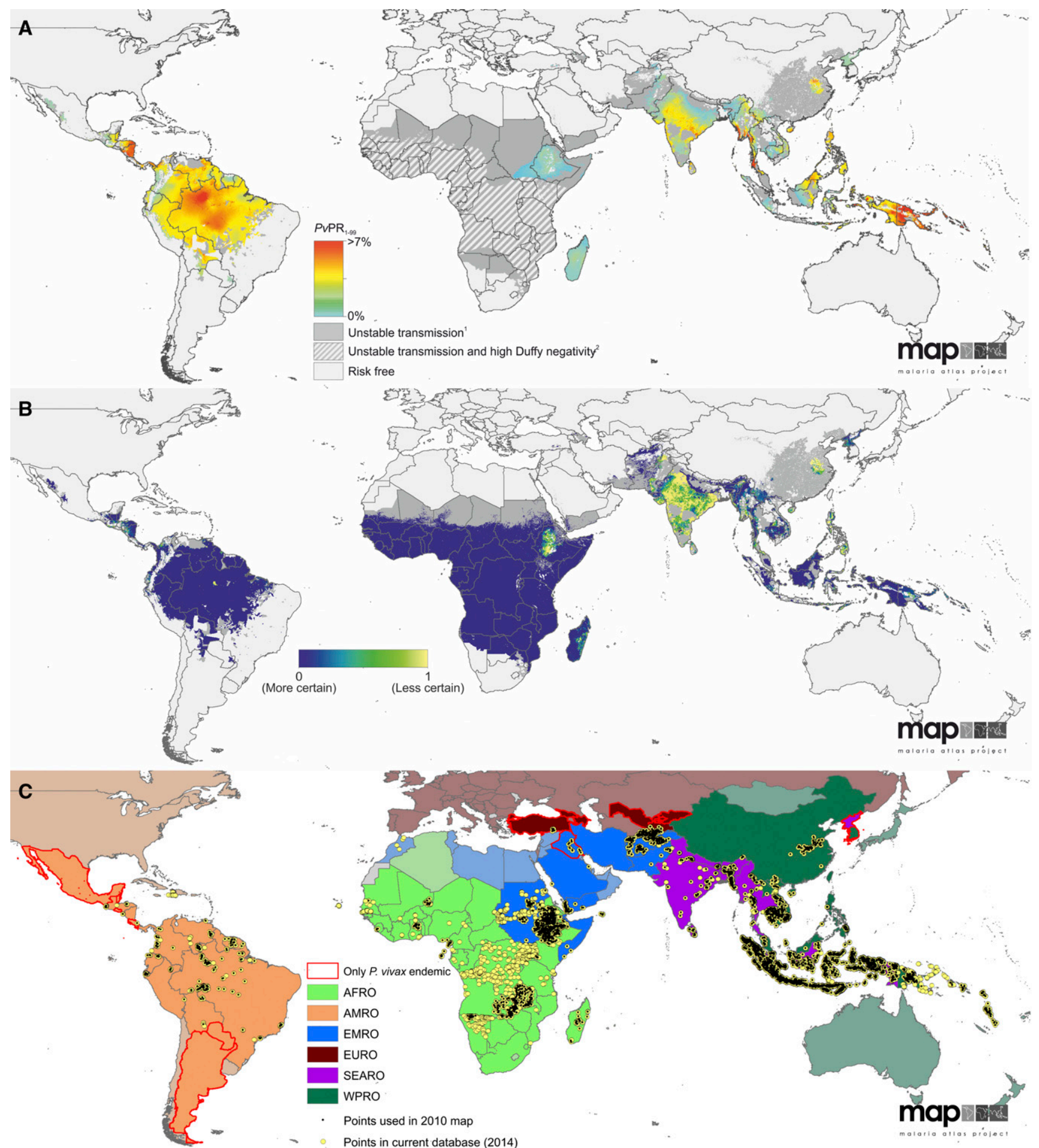

FIgURE 1. The spatial distribution of Plasmodium vivax, associated uncertainty, and input data records. (A) The limits and endemicity of P. vivax in $2010 .^{2}$ Spatial limits of parasite-specific malaria risk are defined by annual parasite incidence (PvAPI) with further medical intelligence, temperature, and aridity masks. Areas were defined as stable, unstable (dark grey areas, $P v$ API $<0.1$ per 1,000 per annum), or no risk (light grey). The model-based geostatistics point estimates of the annual mean predicted prevalence are shown within the spatial limits of stable transmission. Estimates of parasite rate standardized to 1- to 99 -year-olds $\left(P v \mathrm{PR}_{1-99}\right)$ that range from $0 \%$ to $>7 \%$ are shown as a spectrum of blue to red. Hatching indicates areas where Duffy negativity gene frequency is predicted to exceed $90 \%{ }^{28}$ (B) The population-weighted uncertainty as the ratio of the posterior interquartile range to the posterior mean prediction at each pixel on a blue to yellow color spectrum multiplied by the underlying population density and rescaled to $0-1$. Higher values (yellow) indicate areas with high uncertainty and large populations. (C) World Health Organization regions by color: the African region (AFRO) in green, the region of the Americas (AMRO) in orange, the eastern Mediterranean region (EMRO) in blue, the European region (EURO) in burgundy, the southeast Asian region (SEARO) in purple, and the western Pacific region (WPRO) in dark green. The countries in each region that are not endemic for P. vivax are slightly greyed out and shaded a lighter color. Those countries that are endemic only with $P$. vivax malaria are outlined in red. The location of the prevalence surveys that were input into the model that produced the map in Figure 1A is shown as small black points and the surveys conducted since 2010 are shown in yellow, illustrating the increased attention given to $P$. vivax in recent years. 
control and elimination strategy enabled by a relatively modest new set of tools. ${ }^{26}$

\section{GEOGRAPHY OF $P$. VIVAX INFECTION}

Plasmodium vivax occurs across the widest geographic area of the human malarias, extending well beyond the limits of $P$. falciparum into temperate climates. This is enabled by intracellular parasites dormant in the human liver, a safe haven from immune attack during long mosquito-free cold seasons when onward transmission and propagation is not possible.

Plasmodium vivax depends on the Duffy antigen to invade red blood cells. Individuals who do not express the Duffy antigen have, therefore, been considered refractory to P. vivax infection ${ }^{27}$ and the prevalence of Duffy negative populations must be considered in predictions and maps of $P$. vivax endemicity. Plasmodium vivax was long thought to be absent from parts of Africa where the Duffy negative phenotype occurs at very high frequencies. ${ }^{28}$ Recent findings of $P$. vivax infections in Duffy negative patients raise the possibility of an alternative invasion mechanism to Duffy, but further investigation is required to assess the public health significance of these findings. ${ }^{29,30}$ The global map of $P$. vivax presented here takes into account estimates of Duffy negativity prevalence as a proxy of the population refractory to infection. $^{28}$ The regular occurrence of $P$. vivax diagnoses in European and American patients who traveled only to areas of Africa dominated by Duffy negativity, ${ }^{31}$ and a formal review of the evidence of the $P$. vivax transmission in Africa, ${ }^{32}$ emphasizes the importance of resisting the temptation to regard these zones as free of $P$. vivax risk.

Modeled spatial data of $P$. vivax transmission and prevalence, 2,31 the uncertainty of those estimates, and the current data available to inform those predictions are presented as maps in Figure 1. The methods used to generate these figures are described in detail elsewhere. ${ }^{33}$ Table 1 shows estimates of the population at risk (PAR) of infection, calculated by combining the maps of the limits of transmission with gridded population surfaces. ${ }^{34,35}$

Levels of $P$. vivax endemicity vary widely among the World Health Organization (WHO) regions. Outside of Africa, $P$. vivax is the dominant species, with relatively high prevalence of infection in the South-East Asian and Western Pacific regions. ${ }^{36}$ Relatively high endemicity also occurs in most of the Americas, but in much less densely populated areas. Data from which to estimate the geographic extent of $P$. vivax transmission in Africa are limited. ${ }^{32}$ High $P$. falciparum endemicity in much of that continent coupled with high prevalence of Duffy negativity overshadowed collection of $P$. vivax- specific data as a priority. ${ }^{25}$ Indirect evidence from returning travelers suggests that $P$. vivax is present at low endemicity in almost all sub-Saharan African countries. ${ }^{31,32}$

How $P$. vivax transmission may be sustained in populations known to be predominantly Duffy negative is not well understood. However, in the instance of Plasmodium ovale in the Asia Pacific, such chronic endemicity without measurable prevalence is known. ${ }^{37}$ The biology of $P$. vivax, in particular its ability for repeated relapses from a single mosquito inoculation, coupled with the very early emergence of gametocytes in the course of blood-stage infection, perhaps enables parasite survival despite relatively low probability of propagation in blood. Further, population mobility along with immigration may amplify the heterogeneity of the Duffy phenotype and increase the population of vulnerable Duffy-positive hosts able to sustain infection.

Some of the highest predicted $P$. vivax prevalence estimates in 2010 (Figure 1) have a relatively sparse evidence base of survey data for large parts of the world (e.g., Brazil, India, Myanmar, and Papua New Guinea). Twenty of the $95 P$. vivax malaria-endemic countries are in the southeast Asia and western Pacific regions, and their populations comprise $83 \%$ of the global PAR of $P$. vivax.

The prevalence of $P$. vivax predicted within $5 \mathrm{~km}^{2}$ areas globally (Figure 1) was derived from a sample of 9,970 parasite rate (PR) surveys. ${ }^{2}$ Compared with similar predictions for $P$. falciparum, ${ }^{3}$ relatively low prevalence occurs throughout the endemic world. The central tendency of the $P$. vivax PR ( $P v \mathrm{PR})$ estimates, age standardized to the 1- to 99-year age range $\left(P v \mathrm{PR}_{1-99}\right)$, rarely exceeded $10 \% .^{2}$ As shown in Figure 2, the prevalence of $P$. vivax is universally low compared with $P$. falciparum, both in range and median values. The 1-99 age range was applied to $P$. vivax, rather than the 2-10 years range used for $P$. falciparum, ${ }^{3}$ because $P$. vivax cross-sectional surveys were most often conducted in whole populations. ${ }^{2}$ The patterns of $P v \mathrm{PR}$ and $P$. falciparum $\mathrm{PR}$ (Pf PR) by age also differ slightly. Plasmodium vivax prevalence peaks in children aged 2-6, compared with 2-10 for $P$. falciparum. In adults, $P v \mathrm{PR}$ is also lower than $P f \mathrm{PR}$ when considered as a proportion of the peak: $P v \mathrm{PR}$ in adults is roughly a quarter of $P v \mathrm{PR}_{2-6}$ whereas $P f \mathrm{PR}$ in adults is roughly a third of $P f \mathrm{PR}_{2-10}$. PR for either parasite is lower in the whole population than in children, but a direct comparison of PR in children relative to whole populations illustrates that $P$. vivax prevalence tends to be much lower regardless of age group (Figure 3 ).

There are other reasons why $P v \mathrm{PR}$ could be lower than $P f$ PR. Although the prevalence of $P$. vivax in heavily endemic areas may reach or even exceed that of $P$. falciparum, $P$. vivax

TABLE 1

Areas and populations at risk* of Plasmodium vivax malaria in 2010 by World Health Organization region ${ }^{2}$

\begin{tabular}{|c|c|c|c|c|c|c|}
\hline & \multicolumn{3}{|c|}{ Area $\left(\right.$ million $\left.\mathrm{km}^{2}\right)$} & \multicolumn{3}{|c|}{ Population (million) } \\
\hline & Unstable & Stable & Any risk & Unstable & Stable & Any risk \\
\hline African region & 17.36 & 1.47 & 18.83 & 19.23 & 36.80 & 56.02 \\
\hline Region of the Americas & 1.38 & 8.08 & 9.46 & 87.66 & 49.79 & 137.45 \\
\hline Eastern Mediterranean region & 4.24 & 0.60 & 4.84 & 176.11 & 47.37 & 223.48 \\
\hline European region & 0.40 & 0.02 & 0.42 & 15.72 & 1.40 & 17.12 \\
\hline Southeast Asia region & 2.11 & 3.88 & 5.99 & 691.71 & 748.38 & $1,440.09$ \\
\hline Western Pacific region & 3.06 & 1.30 & 4.36 & 533.04 & 81.16 & 614.20 \\
\hline World & 28.55 & 15.35 & 43.90 & $1,523.47$ & 964.90 & $2,488.37$ \\
\hline
\end{tabular}




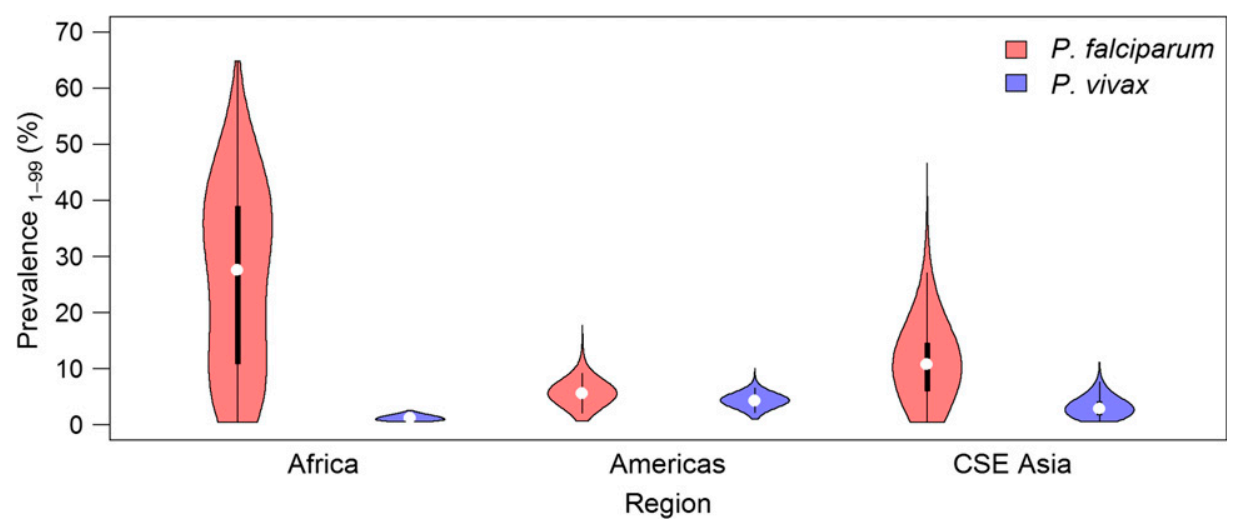

FIgure 2. Comparison of Plasmodium falciparum and Plasmodium vivax prevalence. ${ }^{135}$ Prevalence values from P. falciparum and P. vivax endemicity surfaces ${ }^{2,3}$ standardized to the 1 - to 99 -year age range. ${ }^{72}$ The shaded areas correspond to each species and show a smoothed approximation of the frequency distribution (a kernel density plot) of parasite prevalence within each geographic region. The black central bar represents the interquartile range and the white circles indicate the median values. CSE Asia $=$ Central and Southeast Asia.

can often go undetected. ${ }^{38}$ Low parasite densities lead to high rates of false-negative diagnoses by microscopy or rapid diagnostic tests (RDTs). ${ }^{39}$ Microscopy diagnoses underestimate the true prevalence of blood-stage $P$. vivax in both high- and low-transmission settings. ${ }^{40-47}$ Plasmodium vivax in mixed infections is also often underdiagnosed ${ }^{48}$; lower densities of $P$. vivax in peripheral blood translate into $P$. falciparum being diagnosed before $P$. vivax is spotted by the microscopist.

Another consideration with regard to true versus observed prevalence is the invisibility of the dormant liver stages to any diagnosis. These parasites could be highly prevalent in many endemic settings. A report by Douglas and others ${ }^{49}$ from Thailand offers some evidence of this. Two months after antimalarial treatment of blood-stage $P$. falciparum infection (which would also have been active against blood-stage $P$. vivax parasites), $51 \%$ of patients tested positive for blood-stage $P$. vivax. Given the region's relatively low transmission rate, this suggests a high proportion of hypnozoite-derived infections and provides an estimate of the prevalence of latent $P$. vivax in people having acute falciparum malaria. Further, $P$. vivax may sequester in tissues like bone marrow and the hemopoietic regions of the spleen. ${ }^{5}$ In at least one patient with asymptomatic and microscopically sub-patent parasitemia, the spleen was heavily laden with blood-stage trophozoites of $P$. vivax. ${ }^{50}$

All of these findings recommend caution in comparing prevalence estimates of $P$. vivax and $P$. falciparum based largely on blood-stage infections diagnosed by relatively insensitive means. These may underestimate true prevalence of $P$. vivax far more than $P$. falciparum. The limitations of diagnostics technologies to detect actual parasite density and actual parasite mass in any given host (or population) have been compared with the floating and submerged sections of an iceberg. In this analogy, one may reasonably assign a greater specific gravity to the $P$. vivax iceberg-it is likely that much more of it is submerged (by intrinsically low blood-stage infection and diagnostically invisible parasites sequestered in marrow and spleen or lying dormant in the liver) relative to P. falciparum.

\section{RELAPSE EPIDEMIOLOGY}

The hypnozoites cause multiple clinical attacks from a single bite of a $P$. vivax-infected mosquito. In contrast,
A

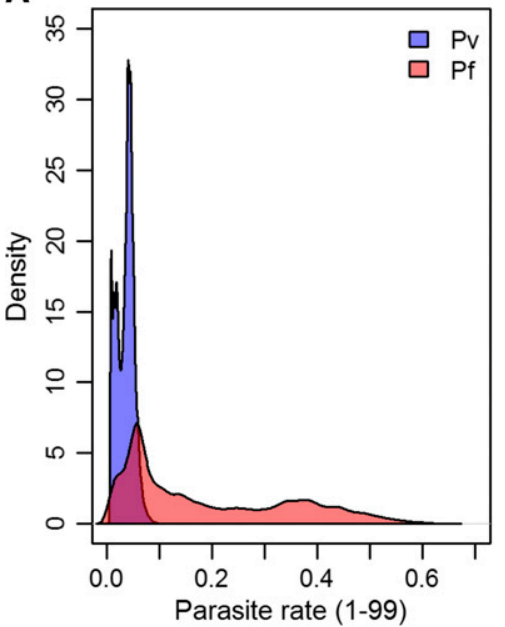

B

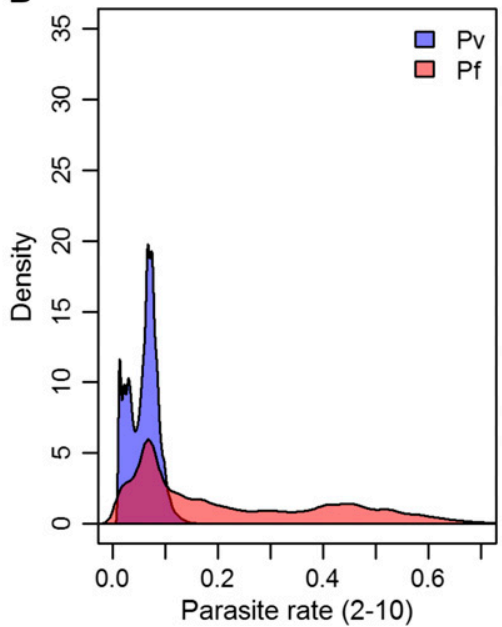

C

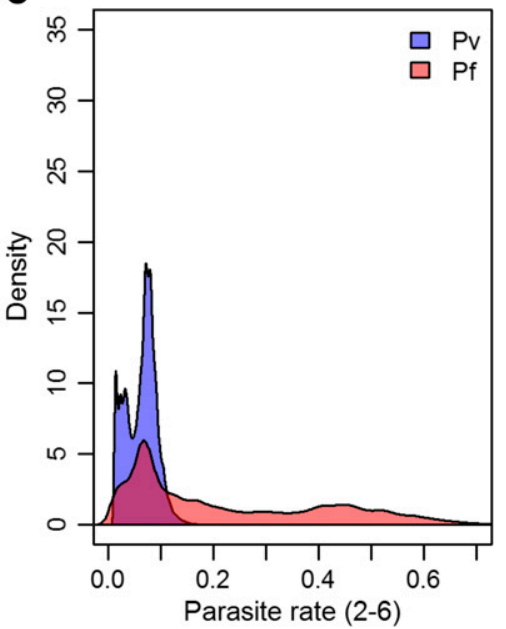

FIgURE 3. Density plots of parasite rate (PR) pixels for Plasmpdium falciparum and Plasmodium vivax in all regions excluding Africa. The plot (A) shows the PR values age standardized ${ }^{72,191}$ to all ages (1-99 years), (B) is standardized to 2- to 10-year-olds, and (C) 2- to 6-year-olds. The plots show that regardless of age, the vast majority of $P$. vivax is found at lower prevalence values. 


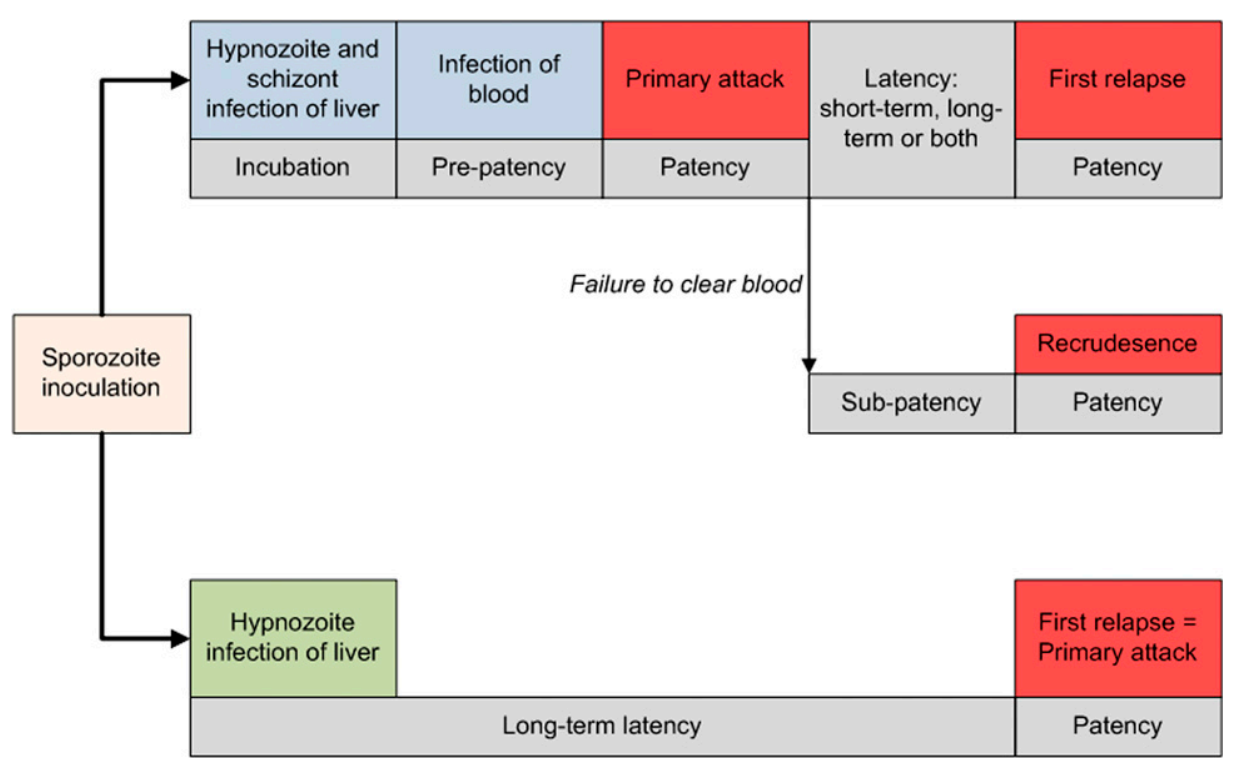

FIgURE 4. Pathways to infection of blood and clinical attacks in Plasmodium vivax malaria. ${ }^{51}$

$P$. falciparum infection of the liver yields a single blood-stage infection. In other words, "infection" as an event in $P$. falciparum is singular and clear, whereas the same in $P$. vivax takes on complex plurality and ambiguity in an epidemiological sense (Figure 4). ${ }^{51,52}$

Recurrence of asexual $P$. vivax parasites in peripheral blood may derive from three distinct sources: relapse (from hypnozoites), recrudescence (from sub-patent asexual parasitemia), or reinfection (by new mosquito inoculation of sporozoites). ${ }^{53}$ Assigning the source of any given parasitemia observed in endemic settings is virtually impossible. ${ }^{54,55}$ Nonetheless, it may be inferred at a population level: the force of infection attributable to sporozoites versus hypnozoites can be estimated through randomized drug trials comparing recurrence rates between treatment arms with and without primaquine. Such investigation in a highly endemic area of Papua New Guinea, where parasites have a short relapse frequency of about a month, ${ }^{51}$ estimated that relapses caused approximately $50 \%$ of blood-stage infections and more than $60 \%$ of clinical episodes in the first 3 months following the drug intervention. ${ }^{56-58}$ Relapse may well be the predominant origin of most $P$. vivax clinical attacks throughout the endemic world.

Geographical variation in the rate and timing at which a "strain" of $P$. vivax may relapse has long been known. ${ }^{59-61}$ Temperate and subtropical strains of the parasite exhibit either a long incubation period or a long delay between the primary infection and relapse (around 8-10 months). Tropical strains are characterized by short incubation times and short relapse intervals. ${ }^{62}$ How hypnozoite relapses are triggered, and the source of this phenotypic variation, remain unknown. ${ }^{39}$ The relapse mechanism may be an adaptive trait of the parasite to sequester or "hibernate" during conditions inhospitable to the Anopheles vectors. ${ }^{63-65}$ Another theory is that latent hypnozoites are activated by systemic febrile illness, ${ }^{65,66}$ which explains observations of multiple relapses at regular (seemingly triggered) intervals, heterologous genotypes in relapse, and what seems to be a high frequency of relapses following $P$. falciparum infections. ${ }^{49,65,67}$ Others hypothesized that a mosquito bite (and its complex immunologic consequences) may trigger relapse. ${ }^{68}$ However, observations from sporozoite-induced infections in North American prisoner volunteers during the 1940s and 1950s indicate relapses occur at predictable intervals and rates, without any known trigger or stimulus. ${ }^{51}$ Further, findings of Shute and others ${ }^{64}$ suggested that individual sporozoites were genetically programmed for either direct tissue development with early primary attack, or for latency and very late primary attack. They observed early primary attacks with the typically long-term latent North Korean strain, but only when the sporozoite inoculum was very high: this strain had relatively high frequencies of sporozoites with genetically set latency, and those set for rapid development were so rare as to not ordinarily occur with the normally low numbers of sporozoites of natural inoculation.

Evidence from records of relapse observed in both controlled experimental and natural settings has demonstrated geographical variation in the timing of relapse. A metaanalysis of over 5,000 first relapse events revealed that epidemiological zones outlined by Macdonald ${ }^{69}$ describe the observed heterogeneity in relapse. ${ }^{51}$ The zones, map, and violin plots in Figure 5 illustrate the variation in time from primary infection to first relapse observed in each area. Although a wide range was observed in almost every zone, some regions had a clear tendency to short or long times to relapse (Figure 6).

Regionally specific relapse patterns should be considered when assessing control and elimination strategy and tactics. The impact of vector control on the incidence and prevalence of $P$. vivax malaria may be less rapid than that observed for $P$. falciparum, with the magnitude of the difference dependent on the relapse phenotype of the region. ${ }^{65}$ Effects may be slowest to materialize in regions characterized by long-latency strains or high rates of relapse (even in areas with shorter latency). The Americas, SouthEast Asia, and Western Pacific WHO regions all harbor strains that relapse quickly and repeatedly following primary infection. The Indian subcontinent and sub-Saharan 

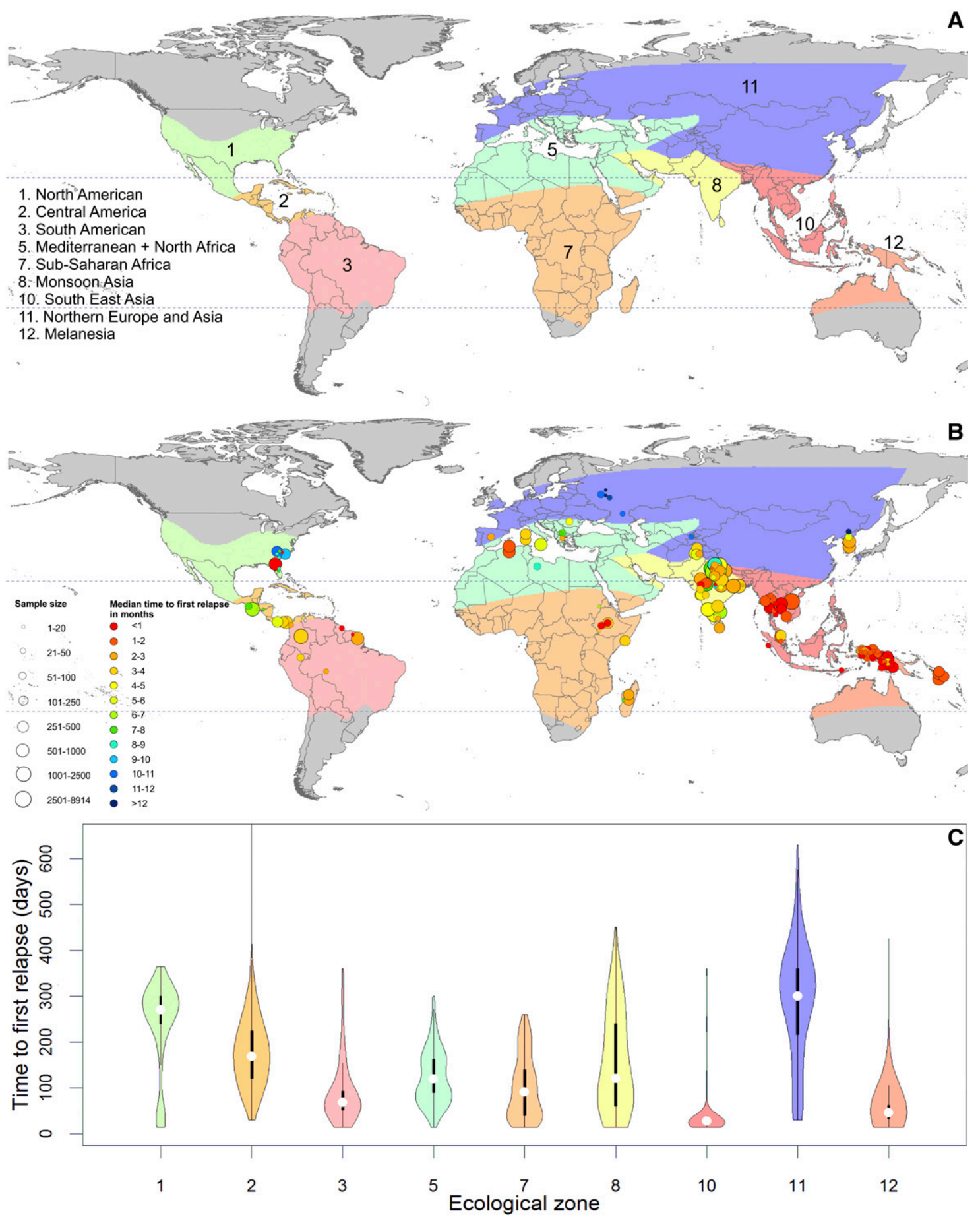

FIgURE 5. Zoo-geographical zones and observed time to first relapse. ${ }^{51}$ (A) The zoo-geographical zones used to describe the time to first relapse. (B) The median observed time to relapse in each study used to obtain individual data. The size of each point varies by sample size and the time to first relapse is shown on a spectrum of red $(<1$ month) to dark blue ( $>12$ months). (C) Violin plots show the observed time to first relapse in individuals from each zone in Figure 5A. The colored areas correspond to each zone and show a smoothed approximation of the frequency distribution (a kernel density plot) of the time to relapse within each geographic region. The black central bars represent the interquartile range, and the white circles indicate the median values.

Africa have variable relapse frequencies and periodicity, but show moderate time to relapse overall. Longer times to relapse are shown in areas around the Mediterranean and Central America, with the longest periods of latency in China and the Korean Peninsula. However, the presence of long-latency strains may be widespread. It is difficult to exclude their presence among multiple frequently relapsing strains in the tropics. ${ }^{65}$ These cautions, coupled with the fears of potential primaquine-induced hemolysis that sharply impede its effectiveness, highlight the complexity 

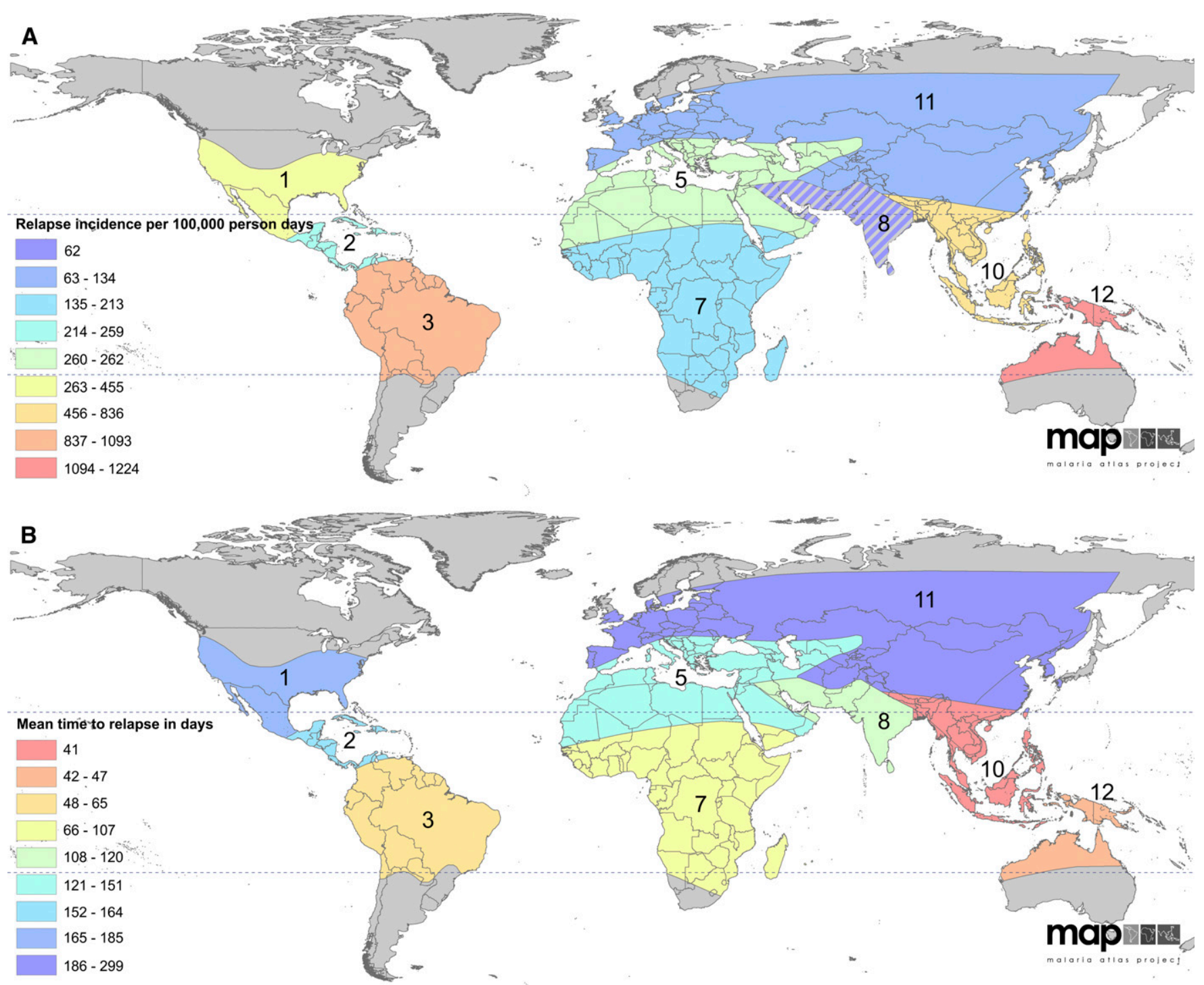

Figure 6. Modeled relapse incidence and mean time to relapse. ${ }^{51}(\mathbf{A})$ The relapse incidence per 100,000 person days on a spectrum of blue to red, with red being the highest incidence of relapse. Zone 8 is hatched to indicate that the prediction is to be interpreted with caution. (B) The predicted mean time to relapse on a spectrum from blue to red, with red being most frequent relapse. The numbers of the zones correspond to those shown in Figure 5A.

and difficulty that relapse brings to $P$. vivax epidemiology and control. ${ }^{70}$

\section{HIGH-RISK GROUPS}

The population groups at highest risk of $P$. vivax infection are determined by immunological factors directly associated with intensity of local transmission, host genetics, and behavioral traits affecting exposure to infectious bites. As such, the primary risk groups differ between epidemiological settings and shift as endemicity wanes toward elimination. ${ }^{71}$ Key risk factors are considered here, though comorbidities and malnutrition, which are discussed later in relation to the clinical aspects of severe disease, are also important risk factors for infection and severe outcomes.

Age. The distribution of Plasmodium infections across a community varies in a predictable pattern as a function of age and transmission intensity. ${ }^{2,4,72}$ In relatively higher endemic areas, young children bear the brunt of disease burden, because by adolescence individuals will have developed immunity against symptomatic disease. In the far more common low-transmission settings, however, infections may not occur frequently enough to allow protective immunity to develop, and in these communities, symptomatic infection is more evenly distributed across age groups. ${ }^{4}$ Figure 7 characterizes these patterns in different endemicity settings. The pattern applies to both $P$. falciparum and $P$. vivax, but studies from co-endemic high-transmission areas of Papua New Guinea and eastern Indonesia report an earlier peak in $P$. vivax cases around 2 years of age compared with 5-10 years for $P$. falciparum, reflecting "faster" acquisition of immunity to $P$. vivax (the role of age per se versus cumulative exposure in these rates is unclear). ${ }^{12,43,73-78}$ In these high-endemicity settings, clinical $P$. vivax is relatively rare in children older than 5 years. This earlier age peak for $P$. vivax has also been 


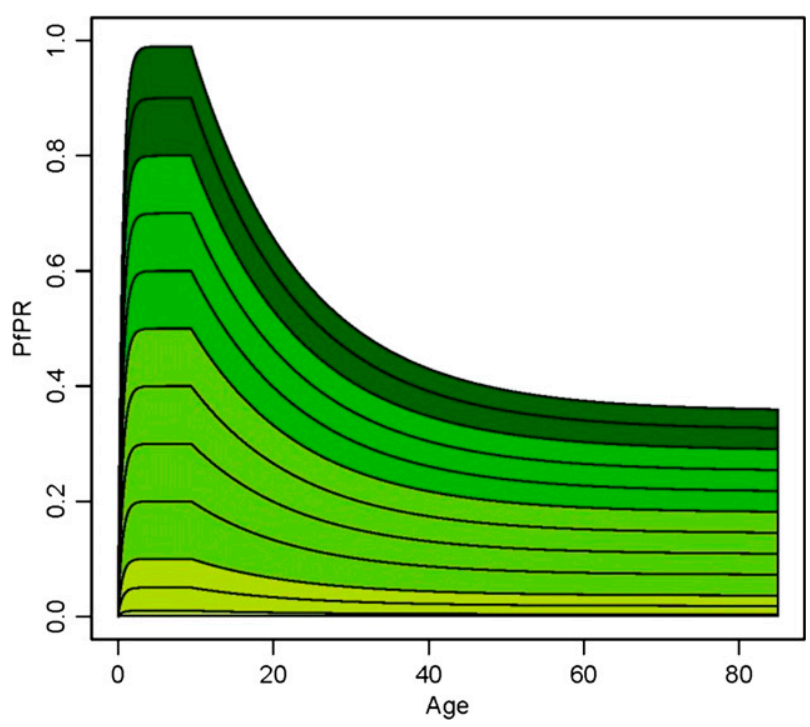

FIGURE 7. Schematic of the age-parasite rate relationship by endemicity class. The curves generated by a model for Plasmodium falciparum (Plasmodium vivax would follow a similar pattern) show the age-parasite relationship at different endemicity levels: holoendemic areas are dark green (category of highest transmission levels), hyperendemicity areas dark grey, mesoendemic areas light grey, and hypoendemic areas very light grey. figure reproduced from Smith and others (2007). ${ }^{72}$

reported from lower transmission intensity settings in Sri Lanka, ${ }^{79}$ Thailand $^{80}$, and Myanmar. ${ }^{81}$ Reasons for this disparity between rates of natural acquisition of immunity against both parasites remain uncertain, ${ }^{4}$ but studies of laboratoryinduced infections during the 1930s suggested that acquisition of immunity with fewer clinical attacks was an intrinsic property of $P$. vivax. ${ }^{82}$ Alternatively, it has also been hypothesized to result from greater exposure to $P$. vivax blood-stage parasitemia due to relapses. ${ }^{11,77}$ Case data from areas nearing elimination (such as Sri Lanka and Malaysia) ${ }^{71}$ also reflect these age shifts in disease burden from young children to all ages as a function of the changing transmission intensity over time. ${ }^{78}$

Ecological setting. Residents of urban areas are generally at lower risk of malaria infection due to man-made ecological conditions that are inhospitable to most Anopheles vector species. ${ }^{2,33,83}$ Anopheles stephensi, common across the Arabian Peninsula and the Indian subcontinent, and east into southern China, is an exception to most malaria vectors in being well adapted to survival in urban habitats. ${ }^{84}$ Evidence discussed in this supplement's review of $P$. vivax epidemiology in India ${ }^{85}$ suggests a trend toward increasing infection prevalence in Indian cities, perhaps tied to land-use changes as part of urbanization construction projects creating breeding habitats and potentially also resulting from greater population movement between urban and rural environments. In addition, the bionomics of the Anopheles mosquitoes in many $P$. vivax endemic areas differ from those within Africa. ${ }^{84,86,87}$ For example, the exophilic and zoophilic tendencies of dominant vector species in Asia render standard malaria control strategies of indoor residual spraying and insecticide-treated nets less effective. ${ }^{84,88}$

Migrant workers represent a risk group of particular priority for malaria control efforts. Many migrants work in highrisk environments such as natural forest, palm oil or rubber plantations, and fish farms. ${ }^{89}$ In areas where major epidemiological shifts toward elimination have occurred, these migrant workers, predominantly adult males, sustain transmission. ${ }^{71}$ Their mobile behavior, together with a range of social, legal, economic, and geographic factors, limits their access to and contact with health-care delivery systems, ${ }^{90}$ putting themselves and those in the areas they live and transit through at sustained risk of transmission.

Pregnancy. Pregnant women and infants are a primary risk group for threatening clinical vivax malaria, ${ }^{91,92}$ resulting in relatively high maternal, infant, and fetal morbidity and mortality. ${ }^{93-95}$ Maternal anemia ${ }^{96}$ increases the risks of premature labor, stillbirth, and reduced birth weight. ${ }^{93,97}$ Studies in Thailand have found severe malaria to be three times (95\% confidence interval [CI]: 1.4-6.2) more common in pregnant than nonpregnant women, ${ }^{98}$ and the odds of miscarriage about three times higher for women infected with either $P$. falciparum (adjusted odds ratio [AOR]: 2.7, 95\% CI: 2.1-3.4) or P. vivax (AOR: 3.1, 95\% CI: 2.4-3.9) than for women with no malaria. ${ }^{99}$ Data from Indonesia suggested that the trigger of severe outcomes was the symptoms of infection rather than the parasitemia per se, and prompt treatment of infections during the first trimester can prevent significant birth weight reductions. ${ }^{96}$ The contraindication of primaquine treatment of pregnant/ lactating women and infants exposes these highly vulnerable groups to the threat inherent in repeated clinical attacks at short intervals. ${ }^{100}$

Host genetic factors. A number of seemingly deleterious human genetic traits affecting red blood cells are found with the highest frequencies in populations across malariaendemic zones. ${ }^{101,102}$ Given this observation, the "malaria hypothesis" suggests these blood disorders may confer protection against malaria disease. ${ }^{103}$ Although most research has focused on $P$. falciparum (especially with sickle-cell disease), some polymorphisms have been found to confer protection against $P$. vivax. For instance, southeast Asian ovalocytosis in Papua New Guinea may confer partial resistance to infection, ${ }^{104,105}$ as may certain variants of glucose-6-phosphate dehydrogenase (G6PD) deficiency. ${ }^{70,106,107}$ In contrast, both alpha and beta thalassemia have been associated with increased risk of $P$. vivax parasitemia. ${ }^{108,109}$ Host genetic factors may, therefore, play a role in determining groups at increased risk of $P$. vivax infection, or groups innately protected from clinical infection, but more $P$. vivax-specific evidence is required to draw concrete conclusions and quantify the altered risk levels.

\section{ASYMPTOMATIC BLOOD-STAGE INFECTIONS}

Asymptomatic blood-stage $P$. vivax infections in populations are often cited as a barrier to control, much like the undetectable reservoir of hypnozoite infections in the liver. This section addresses asymptomatic blood-stage infections, whether arising from sporozoites, hypnozoites, or insufficiently treated primary infections. Infection detectability varies over the time course of $P$. vivax infections, with fever and symptoms usually occurring early, when they occur at all. Depending on the setting, typically a small proportion of blood-stage infections trigger symptoms and treatment seeking, whereas a much larger proportion of infections will be asymptomatic, sub-patent, or dormant. ${ }^{41}$ For infections that are not treated or improperly treated, the resolution of 


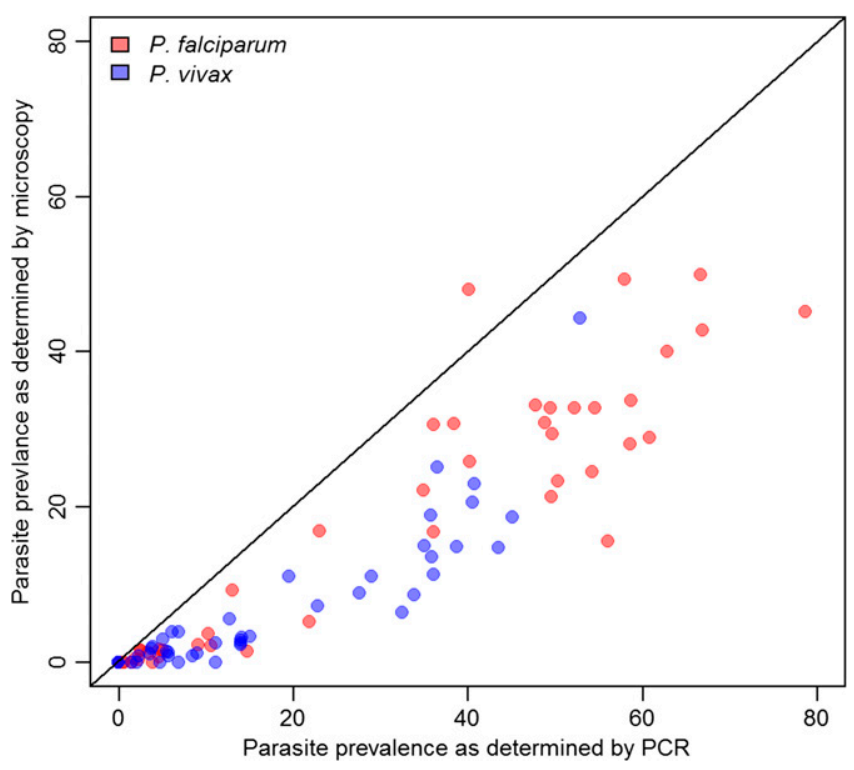

FIGURE 8 . The proportion of infections detected by microscopy versus proportion detected by polymerase chain reactions (PCR) for Plasmodium falciparum and Plasmodium vivax. Derived from data in Okell and others 2012 supplementary information. ${ }^{192}$ Only surveys where both $P$. vivax and $P$. falciparum were detected are shown. Of the 44 data points for each species, all but four were for all age groups-the remaining four considered children under age 5 only.

symptoms is followed by a much longer asymptomatic infection that is progressively less likely to be detected as it ages. Different proportions of asymptomatic and sub-patent infections will be detected based on the survey method (i.e., longitudinal versus cross sectional), the diagnostics used, and the timing of the survey with respect to recent outbreaks or transmission seasonality.

It is not known what proportion of $P$. vivax infections are or will become febrile or otherwise symptomatic, but the majority of $P$. vivax infections in cross-sectional surveys are symptomless and undetectable by standard diagnostic techniques (RDTs and microscopy). ${ }^{4} \mathrm{Up}$ to $97 \%$ of microscopically diagnosed $P$. vivax infections in the Pacific Asia region have been reported to be asymptomatic; higher sensitivity diagnostics, such as polymerase chain reaction (PCR), would likely find an even higher proportion (Figure 8). ${ }^{110,111}$ Similar findings have been reported from Amazonia, India, the Mekong, Indonesia, and the Solomon Islands. ${ }^{47,11-120} \mathrm{~A}$ review of submicroscopic infections detected in 31 crosssectional surveys from 12 countries revealed that on average $69.5 \%$ of all $P$. vivax blood-stage infections were submicroscopic, and in a subset of surveys, $89-100 \%$ of submicroscopic infections were asymptomatic. ${ }^{46}$ The most common type of $P$. vivax infection in many areas is, therefore, both submicroscopic and asymptomatic.

There is no known sterilizing natural immunity to malaria. People with chronic exposure appear to develop a partial immunity (parasitemia without illness) as a function of both age and the intensity of exposure, as discussed previously and illustrated in Figure 9. The proportion of asymptomatic infections may vary considerably in endemic situations. People of all ages, and of very different previous exposure patterns to malaria, have been found to harbor asymptomatic parasitemia. This may be due to parasite and host factors other than host immunity. ${ }^{121}$ The protective natural immunity to infection by both $P$. vivax and $P$. falciparum in very lowtransmission settings is not understood in the context of current thinking on how natural immunity is acquired. ${ }^{122}$

Assessing the contribution of the asymptomatic reservoir to onward transmission has proved challenging, not least due to the methodological difficulties involved. However, Barbosa and others reported gametocytemia in $>90 \%$ of individuals with asymptomatic or sub-patent $P$. vivax in $\mathrm{Brazil}^{123}$; and a study in Colombia including both natural and experimental infections (total patients $N=46$ ) used membrane feeding assays to quantify infectivity and concluded that asymptomatic

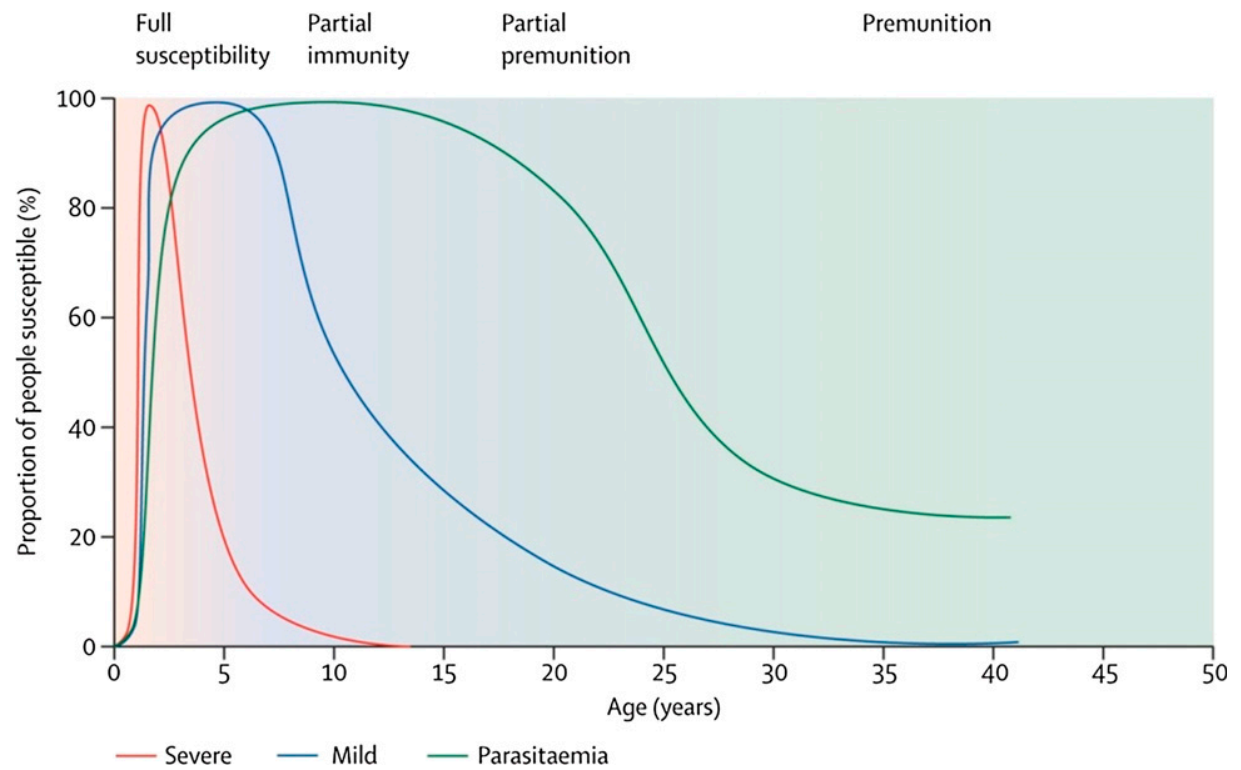

FIGURE 9. Relation between age and malaria severity in an area of moderate Plasmodium falciparum transmission intensity. With repeated exposure, protection is acquired first against severe malaria, then against illness with malaria, and much more slowly, against microscopydetected parasitemia. Figure reproduced with permission from White and others. ${ }^{193}$ 
carriers were at least as infective as symptomatic patients, and also presented with the highest proportions of infectious mature gametocytes. ${ }^{124}$ The association between asymptomatic infection and gametocyte density is essential to understanding transmission dynamics. Plasmodium vivax gametocytes mature faster than $P$. falciparum gametocytes, and may, therefore, be transmitted earlier in the course of infection. ${ }^{23}$ Mosquito $P$. vivax infections occur at lower gametocyte densities than $P$. falciparum, and therefore, a greater proportion of transmission could occur from those with undetectable gametocytemia. ${ }^{125,126}$

The proportion of asymptomatic infections varies with transmission intensity such that in low-transmission settings, there is a higher proportion of asymptomatic carriers. ${ }^{46} \mathrm{By}$ nature of being asymptomatic, these individuals are less likely to be treated, and therefore, asymptomatic infections will persist longer in a population. However, with sustained detection and treatment of symptomatic cases alone, transmission will, in theory, decrease, leading to an associated decrease in population immunity and lower frequencies of asymptomatic infections. ${ }^{127}$ This may be true for both $P$. vivax and $P$. falciparum. Where $P$. vivax presents a greater challenge is the hypnozoite-relapses caused by this undetectable reservoir of infection may be symptomatic or asymptomatic, and are an important source of sustained transmission where control of only blood-stage infections and mosquito interventions are implemented. ${ }^{128}$

\section{ESTIMATES OF THE CLINICAL BURDEN OF P. VIVAX MALARIA}

Reliable measures of the clinical burden of $P$. vivax have been identified as a key knowledge gap. ${ }^{7,39,79}$ Case estimates improve treatment targeting, guide strategic planning for control, and provide a means of monitoring the impact and progress of those interventions. A few attempts have been made to quantify clinical vivax cases, with widely divergent results.

Case estimates. The most recent estimates of $P$. vivax cases, from the WHO's 2015 World Malaria Report, ${ }^{36}$ suggest 13.8 million (95\% CI: 10.3-18.4) P. vivax cases in 2014. This corresponds to $6 \%$ of all malaria cases globally and $51 \%$ of all malaria cases estimated to occur outside of subSaharan Africa. Figure 10 shows the contribution of cases from the highest burden $P$. vivax countries in 2013. Cases from just three countries-India, Pakistan, and Indonesiatogether represented $>80 \%$ of cases globally. Unlike the methodological developments estimating $P$. falciparum case numbers, ${ }^{129,130}$ limited recent efforts have been invested into P. vivax case estimation. Historical estimates based on preyear 2000 data estimated a much larger case burden than the recent WHO figures (71.0-80.0 million annual cases by Mendis and others [2001] based on mid-1990s data ${ }^{79}$; and 132.0-391.0 million estimated by Hay and others [2004] $]^{7,130}$ based on a malaria endemicity map from 2002), but these cannot be considered reliable indicators of contemporary transmission. Robust methods, similar to those developed for $P$. falciparum, are required to overcome the limitations of the available data for estimating $P$. vivax cases.

Quantifying case numbers. In the context of varied data sources (all of them imperfect in important respects), differing methods have been used to derive case burden estimates. The WHO primarily follows a surveillance-based approach

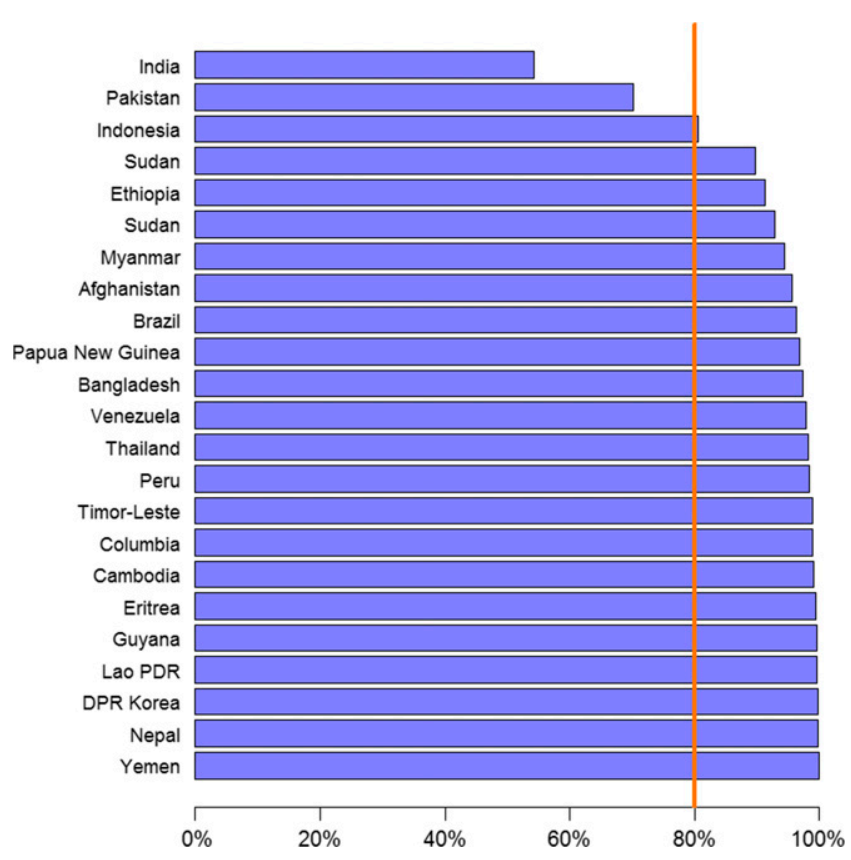

Figure 10. Cumulative proportion of the global estimated Plasmodium vivax cases accounted for by the countries with the highest number of cases. Reproduced from the World Malaria Report 2014. ${ }^{132}$ Lao PDR refers to Lao People's Democratic Republic and DPR Korea to Democratic People's Republic of Korea.

using health facility records reported to each country's Ministry of Health. ${ }^{131}$ The accuracy of reported cases is influenced by reporting completeness, treatment-seeking behavior, and the likelihood that a case of malaria is found to be parasite positive, all of which are adjusted for using country-specific parameters. However, for countries with less reliable routine surveillance data, model-based methods that link measures of malaria transmission with case incidence are used instead. The WHO's approach, therefore, strives to cope with the variability in diverse sources and variable quality of reported data. ${ }^{131,132}$

Other epidemiologists have investigated alternative approaches based on a widely available and easily obtained epidemiological metric, the prevalence of infection (or PR). This represents the proportion of individuals infected (confirmed by microscopy or RDT) in an area at a fixed time point as measured by cross-sectional surveys. ${ }^{133}$ This metric was used to map the global prevalence of $P$. vivax endemicity (Figure 1$){ }^{2}$ Case estimates can then be derived from the prevalence map by using a model of the relationship between prevalence of infection and clinical incidence. ${ }^{129,130,134-136}$ Figure 11 represents such a model developed for $P$. vivax that will be integrated into a cartographic approach to derive estimates of $P$. vivax clinical cases. ${ }^{135,137}$ This approach quantifies the degree of uncertainty in the predictions, highlighting regions in need of improved surveillance. Preliminary work by the authors shows that these results are of the same order of magnitude as the estimates provided by the WHO using routine surveillance data.

These alternative approaches to case estimating provide complementary and useful comparisons in continuing to leverage much-needed improved $P$. vivax surveillance and reporting.

Trends of $\boldsymbol{P}$. falciparum and $\boldsymbol{P}$. vivax case count ratios. It has been noted during successful control campaigns that 

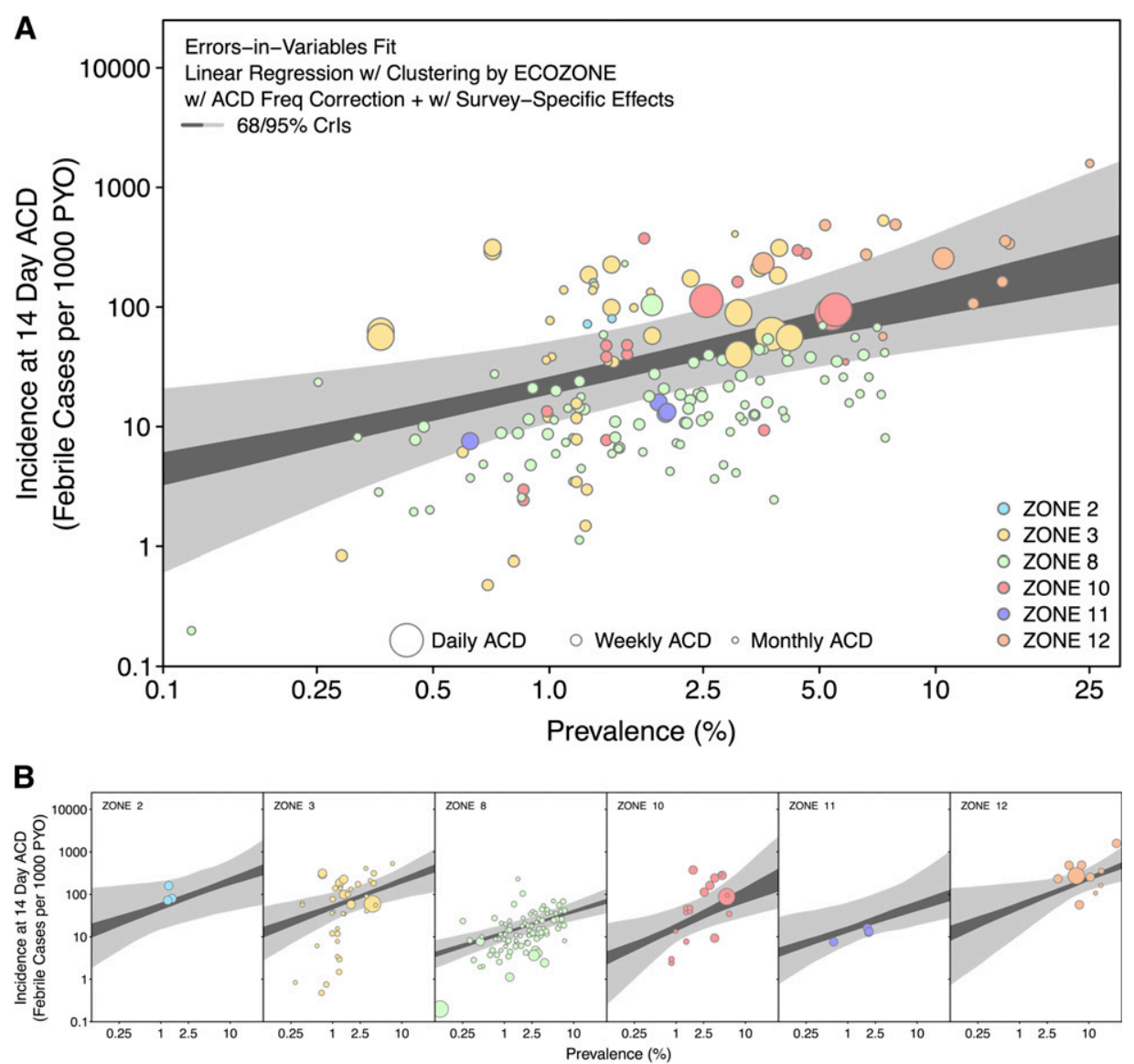

Figure 11. Modeled relationship between parasite prevalence and clinical case incidence for Plasmodium vivax. (A) The pooled prevalenceincidence relationship as point-wise $68 \%$ and $95 \%$ credible intervals (CrIs) based on data from all zones (Figure 5). To produce a pooled fit, the posterior of each zone was weighted by the number of observations from that zone. (B) The zone-specific prevalence-incidence relationships. Zone 2 is Central America, zone 3 is South America, zone 8 is Monsoon Asia (India), zone 10 is southeast Asia, zone 11 is northern Asia and Europe, and Zone 12 is Melanesia. The $95 \%$ CrIs are shown in light grey and the $68 \%$ CrIs in dark grey. The colors of the zones correspond to those shown in Figure 6B. Reproduced from Battle and others. ${ }^{135}$

P. falciparum is often the first species to show a decline in incidence, with $P$. vivax generally being slower to respond. In addition to relapse, this is also likely due to 1 ) the longer extrinsic incubation period of $P$. falciparum compared with $P$. vivax, meaning that transmission of the former is more susceptible to interventions such as insecticide-treated bed nets and indoor residual spraying which shorten the average lifespan of the vector population; ${ }^{138}$ and 2) the fact that infectious gametocytes appear early in a blood-stage infection of $P$. vivax, almost simultaneously with asexual parasites, in contrast to $P$. falciparum in which mature infective gametocytes take 10 days to appear in the peripheral blood after asexual parasite patency. ${ }^{79}$ This means that when a $P$. vivax-infected patient presents for diagnosis and treatment, onward transmission of the parasite could have already occurred and the early diagnosis and treatment strategies that are highly effective against $P$. falciparum may not be so for $P$. vivax. ${ }^{79}$

The phenomenon of the proportion of cases due to $P$. vivax increasing as overall cases decrease has been observed in a variety of endemic settings. ${ }^{71}$ Observations from Thailand, ${ }^{139}$ Sri Lanka, ${ }^{140}$ and Brazil ${ }^{141,142}$ showed the proportion of cases due to $P$. vivax greatly increased as control efforts were scaled up over time. This pattern is not always obvious from national-level data, however, because control programs are not focused uniformly across a country. Areas with the highest transmission intensity (often with more $P$. falciparum) may have fewer services available and $P$. vivax, therefore, appears to decrease more quickly as control is applied to lower transmission areas. Nonetheless, the pattern of an increasing proportion of cases due to $P$. vivax in elimination settings has also been observed in a variety of settings. ${ }^{47,71,140,143}$ All countries in the WHO 2013 World Malaria Report that reported microscopically confirmed cases found a higher proportion of $P$. falciparum in years with higher case numbers than in years with fewer. ${ }^{143}$ In addition, $P$. vivax was the predominant species in countries in pre-elimination and elimination phases which have a low total annual malaria incidence rate (Figure 12). ${ }^{144,145}$

In general, decreases in the incidence of $P$. falciparum cases have been larger than those of $P$. vivax. ${ }^{143}$ Biological characteristics unique to $P$. vivax cause existing control strategies, particularly treatment options, to be less suitable in the final, predominantly $P$. vivax, elimination stages. ${ }^{71}$ The consistency of this phenomenon serves to emphasize the programmatic significance of the biological distinctions between $P$. vivax and $P$. falciparum, with malaria control having been historically aimed principally at $P$. falciparum without regard to the singular biology of $P$. vivax. Programs aiming for more 


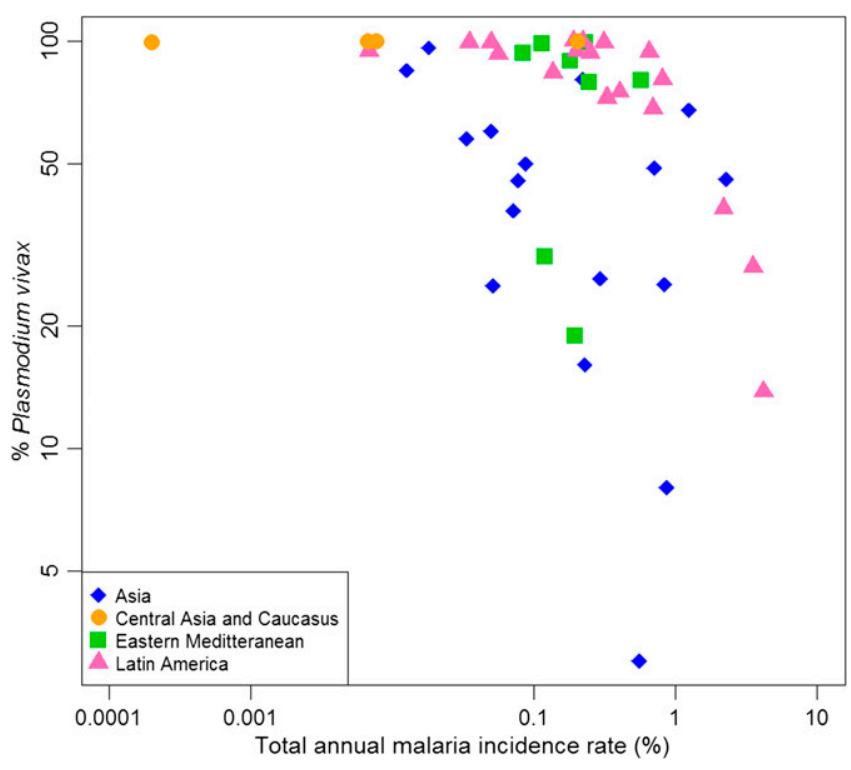

Figure 12. The variation of the proportion of malaria cases due to Plasmodium vivax with the annual malaria incidence rates in endemic countries, as published in 2001 (the rest being mainly due to Plasmodium falciparum) shown on a logarithmic scale. The data points are color coded and shaped by region. Asia includes Bangladesh, Bhutan, Cambodia, China, Lao People's Democratic Republic, Malaysia, Myanmar, Nepal, Papua New Guinea, Philippines, Solomon Islands, Sri Lanka, Thailand, Vanuatu, and Vietnam. Central Asia and Caucasus includes Armenia, Azerbaijan, Tajikistan, and Turkey. Eastern Mediterranean refers to Afghanistan, Iran, Iraq, Oman, Pakistan, Saudi Arabia, Syria, and Yemen. Latin America includes Argentina, Belize, Bolivia, Brazil, Colombia, Costa Rica, Dominican Republic, Ecuador, El Salvador, Guatemala, French Guyana, Guyana, Haiti, Honduras, Mexico, Nicaragua, Panama, Peru, Suriname, and Venezuela. The percentage of $P$. vivax for each country is as cases reported by the countries to World Health Organization. Note that the figure excludes data from the African region because high prevalence of the Duffy negativity phenotype results in very low $P$. vivax transmission $^{28}$ and occasional case reports of $P$. vivax are vastly outnumbered by $P$. falciparum cases. Figure modified from the original published version, ${ }^{79}$ and shared by Kamini Mendis.

rapid and thorough elimination of malaria transmission should adapt their strategies and interventions toward effectiveness against $P$. vivax; without these, standard interventions will have to be sustained over much longer periods to drive out $P$. vivax transmission. ${ }^{25,143,146}$

\section{SEVERE AND FATAL $P$. VIVAX MALARIA}

The last decade saw a significant shift in knowledge, attitudes, and practices toward P. vivax. Having long been characterized as the "benign tertian" malaria, 6,7,147-149 recent evidence demonstrates that a diagnosis of $P$. vivax infection can be associated with severe and fatal illness. ${ }^{5,8-20}$ In consequence, the species begins to become acknowledged as inherently pernicious.

The nature of severe and fatal vivax disease. In the absence of a species-specific case description for severe $P$. vivax ${ }^{150}$ the WHO case definition for severe $P$. falciparum malaria (excluding parasite counts) has been widely applied for categorizing uncomplicated versus severe disease in patients diagnosed with $P$. vivax infection. The spectrum of clinical syndromes for both species is essentially similar. ${ }^{8}$
Studies of vivax morbidity and mortality from across the vivax-endemic world have reported the full spectrum of pathologies commonly attributed exclusively to $P$. falciparum, including both sequestration-related and nonsequestrationrelated complications. ${ }^{13-16,149,151-153}$ A diagnosis of acute severe vivax malaria, therefore, includes one or more of the following (numerous case reports of each exist in the literature $)^{8,10,13,19,149,154,155}$ : 1) neurological conditions, notably coma or repeated general seizures and altered consciousness; 2) hematological conditions, particularly severe anemia ( $<5 \mathrm{mg} \mathrm{Hb} / \mathrm{dL})$, severe thrombocytopenia $(<50,000$ platelets/ $\mu \mathrm{L}$ ), and hemoglobinuria; 3) systemic symptoms such as circulatory collapse or shock; and 4) vital organ failure, including respiratory dysfunction and acute respiratory distress syndrome, acute renal failure, splenic rupture, hepatic dysfunction, and jaundice.

The preponderance of each syndrome among severely ill patients with $P$. vivax or $P$. falciparum infection differs, and risk of death differs greatly between syndromes. ${ }^{20}$ For instance, metabolic acidosis, coma, and other neurological complications occur less frequently in severe vivax malaria, whereas severe anemia and acute lung injury are more commonly reported manifestations of severe $P$. vivax. ${ }^{8,14}$ Respiratory distress was associated with 15 of $17 P$. vivax mortalities in an autopsy series in Brazil ${ }^{14}$ and in Indonesian Papua, severe anemia dominated as the cause of illness among inpatients. When severe anemia occurred with respiratory distress, death became a likely outcome (OR: $65, P<0.0001) .{ }^{20}$ Despite lower peripheral blood-stage parasitemia, the degree of anemia in severe $P$. vivax and $P$. falciparum infections is often similar. ${ }^{11}$

A recent global meta-analysis of 77 studies comprising 46,411 severe vivax patients revealed marked geographic patterns in the prevalence of particular clinical manifestations of severe vivax. ${ }^{153}$ Noteworthy was the apparently much lower incidence of severe disease in certain regions, including the Greater Mekong, than others such as India, where nearly half of the severe vivax studies were conducted. The broad pattern identified was that in high-transmission areas (such as New Guinea), severe anemia was the predominant symptom and found mainly in young infants. ${ }^{12,76}$ In lower endemicity areas (such as parts of the Americas), where adults were more likely to be affected, patients presented with a variety of vital organ dysfunctions. ${ }^{153}$ Strain-dependent virulence in $P$. vivax is well known and far more striking than in P. falciparum. ${ }^{5}$

Evidence of the risks of severe and fatal $\boldsymbol{P}$. vivax. The risk of severe disease and case fatality rates (CFRs) are not firmly established for $P$. vivax. Although the WHO severe $P$. falciparum criteria apply to characterizing severe vivax, formally defining specific criteria and thresholds remains necessary to ensure consistency between studies and enable meta-analyses of the prevalence of severe disease and risks of morbidity from different manifestations of disease to be more robustly assessed. ${ }^{153}$ The risk of a $P$. vivax infection presenting severe symptoms is difficult to quantify because of the inherent difficulty in estimating the number of $P$. vivax infections in a community (the denominator of this risk estimate). Recent studies aiming to quantify rates of severe disease and fatality used varying metrics to represent "total $P$. vivax cases," including hospital cases,${ }^{20}$ community surveyed infections, ${ }^{156}$ and regional case notifications. ${ }^{19,157}$ The discrepancies in the number of cases captured through community 
surveys and those reporting to hospital make comparing rates of severe disease and death between studies difficult.

The risk of fatality among hospitalized $P$. vivax cases was summarized in 16 studies by Baird, ${ }^{5}$ of which 10 were retrospective and six prospective. Using these data and an additional 27 studies with documented species-specific numbers of severe disease and death, the median CFR among inpatients with severe disease was found to be $3.1 \%$ (interquartile range [IQR]: $0.0-9.3 \%) .{ }^{158}$ Five of these studies were able to rule out the possibility of a mixed infection with $P$. falciparum using PCR. The median CFR from severe $P$. falciparum disease where it occurred and was reported among 22 of the same hospitals was $11.6 \%$ (IQR: 4.9$22.8 \%$ ). The odds of an inpatient dying from a $P$. vivax malaria infection were just under two-thirds that of those with severe $P$. falciparum infections (OR: 0.63, 95\% CI: $0.52-0.77)$. This ratio is unlikely to reflect the relative risks of dying among patients who acquire malaria in the community. Nonetheless, the studies do show that severe cases and deaths due to $P$. vivax can occur in all endemic regions.

Population-based risks of death have rarely been compared between parasites. Where they have, the risk with $P$. vivax was less than half that associated with $P$. falciparum. ${ }^{20}$ This large prospective population-based study $(N=45,525$ clinical $P$. vivax cases) estimated the risk of severe disease to be one in 270 clinical episodes, and death was one in 3,959. The equivalent risks among 72,721 clinical episodes of $P$. falciparum were one in 185 and one in 1,742, respectively, illustrating a significantly different risk of death between species. Nonetheless, this study and many others firmly support abandoning the dogma that $P$. vivax is an intrinsically benign and generally harmless species.

Comorbidities and malnutrition. Although it is apparent that $P$. vivax mono-infections can be associated with severe and fatal illness, ${ }^{5,14,151}$ coinfections with other pathogens may be playing important roles influencing the likelihood of those poor outcomes, as reported with $P$. falciparum. ${ }^{159-161}$ The Brazilian autopsy study previously mentioned ${ }^{14}$ identified comorbidities as important in 13 of the 17 deaths considered. Similarly, a series of Brazilian intensive care patients reported over half of those admitted with a primary diagnosis of $P$. vivax malaria, $(14 / 24)$ suffered at least one acute or chronic comorbidity. ${ }^{16}$

Few studies have described comorbidities with $P$. vivax. Understanding the impact of coinfections on clinical outcome is nonetheless vital to assuring appropriate treatment courses and case management, as has been demonstrated with $P$. falciparum. ${ }^{159}$ For instance, dengue and $P$. vivax show spatial overlap in distributions ${ }^{2,162,163}$ and their coinfection presents significant diagnostic and treatment challenges. ${ }^{164-168}$ Another important geographically overlapping family of pathogens is the soil-transmitted helminths (STHs) that also cause anemia, ${ }^{165-169}$ but only a handful of studies have examined their association with $P$. vivax. A study of Brazilian schoolchildren found STHs had a protective effect against severe anemia during $P$. vivax infections, ${ }^{170}$ whereas a study of pregnant women on the Thai-Myanmar border reported a reduced risk of clinical vivax cases (AOR: 0.29, 95\% CI: 0.11-0.79) in women infected by Ascaris lumbricoides, but not with other STH species. ${ }^{171}$ Further work is needed to better understand these apparently complex interactions and how control and treatment should be adapted to account for the coinfection. As highlighted by Boel and others, a poten- tially negative impact of mass deworming programs on the pathogenesis of $P$. vivax disease severity complicates and leaves unclear the use of control interventions without fully understanding the interactions between coinfections. ${ }^{171}$

Malnutrition is also an important predisposing factor for severe outcomes of $P$. vivax infection and is commonly diagnosed in severe vivax malaria patients globally. ${ }^{13,16,155,172}$ Given the high prevalence of malnutrition across malariaendemic zones, further studies are needed to better establish the risks of $P$. vivax disease associated with malnutrition, and the programmatic possibilities for interventions addressing these simultaneously.

\section{EPIDEMIOLOGY OF CHLOROQUINE-RESISTANT P. VIVAX}

Chloroquine has been the frontline drug for treating asexual blood-stage $P$. vivax parasites during acute clinical attacks since $1946 .^{53}$ Administered in combination with the hypnozoitocidal drug primaquine, this drug combination provides radical cure of $P$. vivax infection by also killing the hypnozoites responsible for relapses. Despite growing evidence of chloroquine resistance across heavy-burden $P$. vivax regions, this drug combination remains the first-line treatment in many countries. ${ }^{36}$ Chloroquine resistance poses a major and worsening threat to the health of millions of patients. A fuller technical description of this problem may be found in the article on diagnosis and treatment of $P$. vivax by Price and others in this supplemental volume. ${ }^{173}$ What follows here summarizes the problem in an epidemiological context.

Defining chloroquine resistance. The standard chloroquine total dose of $25 \mathrm{mg} / \mathrm{kg}$ is administered as three daily doses. ${ }^{174}$ This typically clears chloroquine-sensitive blood-stage $P$. vivax parasites within 48 hours. The relatively slow in-host elimination of chloroquine sustains minimally effective concentrations against sensitive $P$. vivax in blood for approximately 35 days. ${ }^{53}$ Any recurrence with chloroquine administered at $100 \mathrm{~nm}$ concentration at this dosing may be classified as resistant regardless of its life-stage origin (recrudescence, relapse, or reinfection; see Figure 4). ${ }^{175}$ A 28-day in vivo test for chloroquine resistance has been adopted based on this rationale, ${ }^{175-177}$ and the 28-day cumulative incidence of recurrences with $>100 \mathrm{ng} / \mathrm{mL}$ chloroquine and its major metabolite, desethyl chloroquine, is the current standard metric for risk of treatment failure due to parasite resistance to chloroquine.

The epidemiology of chloroquine resistance. The first report of $P$. vivax chloroquine resistance dates to 1989 in Australian travelers visiting Papua New Guinea. ${ }^{178}$ High-grade chloroquine resistance has been described in and around this area, ${ }^{174,179-182}$ and evidence of resistance is now reported from many high-burden countries across all three endemic continents, ${ }^{182}$ including the Americas. ${ }^{183}$ Figure 13 illustrates the findings from the relatively scant surveys reported globally up to April 2014.

The WHO have standard protocols for therapeutic efficacy surveys for the routine monitoring of drug sensitivity to inform national drug policies. ${ }^{177}$ Nevertheless, more detailed meta-analyses of research studies aiming to monitor the spread of resistant strains globally are currently hindered by both variability in survey design and the paucity of them. ${ }^{182}$ 

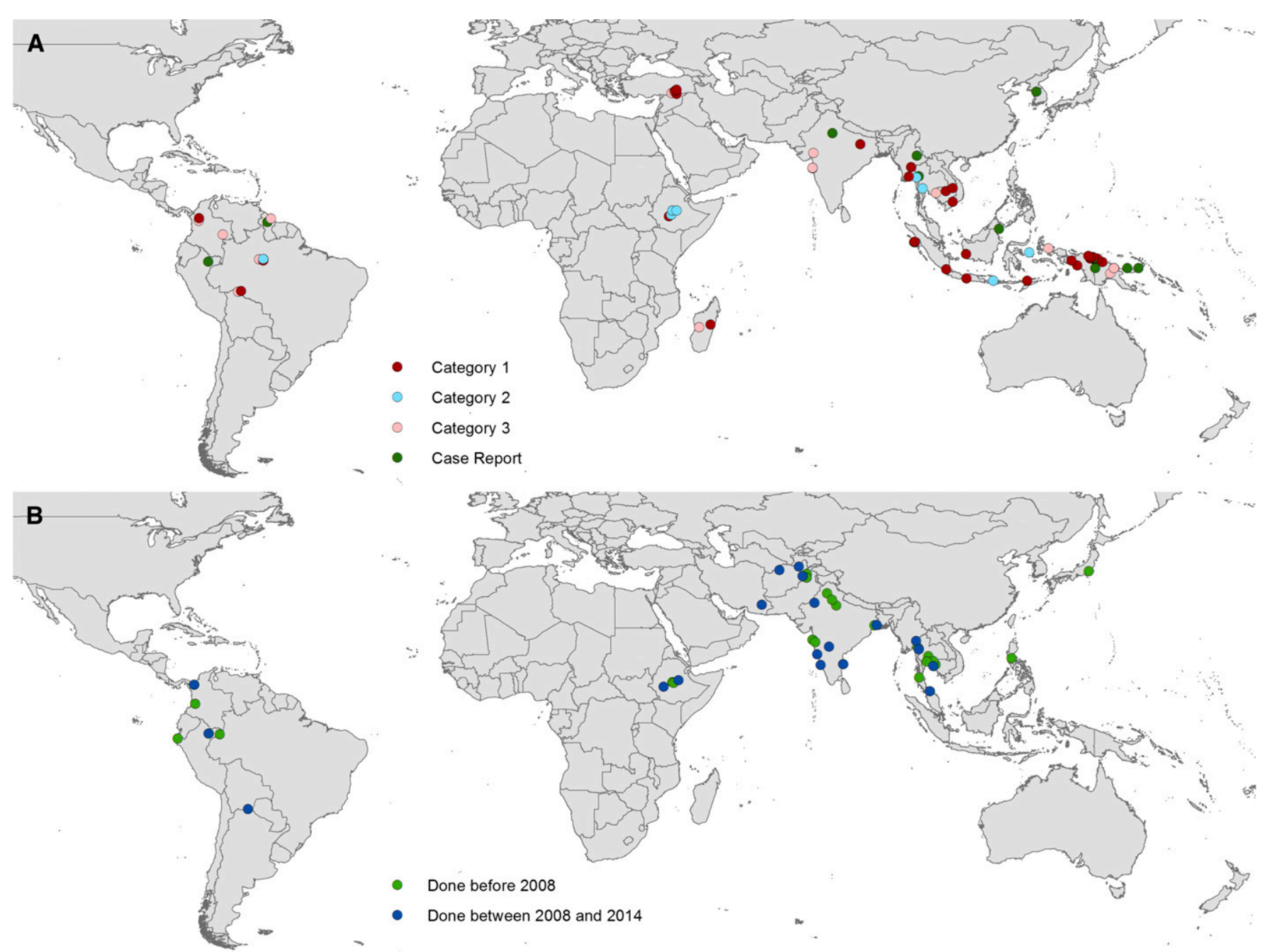

FIGURE 13. The locations of (A) documented chloroquine-resistant and (B) chloroquine-sensitive Plasmodium vivax. Chloroquine resistance was categorized according to the strength of evidence ${ }^{182}$ : Category $1:>10 \%$ recurrence by day 28 , irrespective of confirmation of adequate blood chloroquine concentration; Category 2: confirmed recurrences by day 28 within reported whole-blood chloroquine concentration of $>100 \mathrm{~nm}$; and Category 3: $>5 \%$ recurrences by day 28 , irrespective of chloroquine concentration. Chloroquine sensitivity was confirmed if patients had enrolled after a symptomatic clinical illness, fewer than $5 \%$ recurrences had occurred by day 28 , no primaquine was given before day 28 , and studies had a sample size of at least 10 patients. Case reports were observations in individual patients of treatment failure during chloroquine prophylaxis, prolonged parasite clearance or P. vivax recurrence following treatment. Figure reproduced from Price and others. $(2014) .{ }^{182}$

Further, ineffective chloroquine treatment because of poorquality drugs represents a confounding factor in assessing resistance. A review of antimalarial drug quality assessments found that $27 \%$ of 2,182 chloroquine samples failed a quality test. ${ }^{183}$ Although many of these surveys were on drug samples from sub-Saharan Africa, Asian countries were also well represented in the review. The issue of substandard drugs adds a further dimension of complexity to monitoring chloroquine resistance in the field.

The clinical implications of chloroquine resistance. Ineffective therapy due to resistance causes an increased burden of disease by extending the duration of clinical symptoms, thus increasing the likelihood of onset of severe and threatening illness and the probability of onward transmission. The neglect of $P$. vivax research and development investments has left a void of $P$. vivax-focused clinical trials and thus few validated alternative treatment options. Evidence of resistance prompted shifts in antimalarial policy, driving countries to turn to new and untested drug combinations with artemisinincombined therapies (ACT) to replace chloroquine. ${ }^{185,186}$ However, a recent review of ACT efficacy and safety from 35 studies in 13 countries across three continents reports good efficacy against asexual blood stages of $P$. vivax (except those ACTs employing pyrimethamines). ${ }^{136,187}$ Primaquine administered 25 days following dihydroartemisinin plus piperaquine was determined safe and effective as a radical cure. ${ }^{136}$ An important hurdle to scaling-up these new treatments and preventing ongoing circulation of ineffective treatment, however, is the greater cost associated with ACT treatment (\$0.92-3.85 per adult course) over chloroquine $(\$ 0.07) .{ }^{187}$ See Price and others for further discussion of the clinical aspects of these issues. ${ }^{173}$

There is at present no conclusive evidence of $P$. vivax developing resistance against primaquine; not least because attributing treatment failure to primaquine resistance is not straightforward. ${ }^{188}$ This is in part due to the complex 
metabolism of primaquine in the human host, which directly determines the availability of drug metabolites active against the parasites. Evidence of a potentially quite common "poor metabolizer" human phenotype of CYP2D6 results in treatment failures that should not be attributed to resistance. ${ }^{189}$ The inability to obtain practical and reliable estimates of the prevalence and distribution of resistance to primaquine by $P$. vivax hypnozoites leaves us blind to this potentially important problem.

\section{CONCLUSIONS}

The epidemiology of $P$. vivax cannot be conveniently defined by a simple set of characteristics and patterns. Instead, it is highly heterogeneous between settings and populations, influenced by a plethora of features including local mosquito vector species, transmission intensity, relapse behaviors, host risk factors, availability and efficacy of treatment, malnutrition and prevalence of comorbidities, to name a few. This article has attempted to draw generalities where possible, but also emphasize key variability. The consequence of this heterogeneity is that a single rule book cannot guide control programs everywhere: strategies must vary according to each area's local epidemiology, and evidence is needed from across these different settings to allow programs to target local requirements. This had been lacking, but recent years have seen a surge of interest and funding specifically focused on $P$. vivax. Studies are now being carried out across the $P$. vivax-endemic world to address the knowledge gaps referred to in this review and to allow local control strategies to be optimized. See the paper in this supplement detailing those research gaps (Bassat and others). ${ }^{190}$

Relapsing hypnozoites mean that significant reductions in $P$. vivax case burden may only become evident a few years after decreases of $P$. falciparum, due to the hidden reservoir of silent $P$. vivax parasitemia. Control and elimination of $P$. vivax, therefore, demands persistence and long-term commitment. Furthermore, the hidden iceberg of both submicroscopic asymptomatic parasitemia and hypnozoites make currently available tools insufficient to assess the true prevalence of infection. Improved surveillance and hospital-based studies may help to unravel the relationships between different epidemiological metrics to allow better estimates of asymptomatic infections, uncomplicated cases, severe cases, and deaths.

Treatment inadequacies severely hinder $P$. vivax control. Continued treatment with chloroquine in areas of known resistance puts millions of patients at risk, whereas radical cure with primaquine is not widely used due to the rational fear of harm to G6PD-deficient patients. ${ }^{70,125}$ Widespread safe access to radical cure would help overcome the resilience of endemic $P$. vivax to control efforts and could substantially impact the parasite reservoir.

A clearer picture of $P$. vivax malaria as a widespread and potentially severe and fatal infection is emerging. We may confidently state that infection by $P$. vivax is certainly not universally "benign." Recognition of the potential for $P$. vivax to cause severe disease or mortality, combined with the sheer scale of the PAR of infection (35\% of the global population) and the imperfect toolkit available to fight $P$. vivax, begin to define a very serious clinical and public health problem in urgent need of greater attention.
Received February 24, 2016. Accepted for publication April 19, 2016.

Published online July 11, 2016.

Acknowledgments: We acknowledge Ric Price for his input on chloroquine resistance, Michael White for his discussions on case estimates, and Joshua Longbottom, Maria Devine, and Alexander Rhodes for comments and proofreading.

Financial support: Funding for Simon I. Hay is provided by a Senior Research Fellowship from the Wellcome Trust (095066), which also supports Katherine E. Battle and Rosalind E. Howes. Simon I. Hay is also funded by grants from the Bill and Melinda Gates Foundation (OPP1119467, OPP1106023, and OPP1093011). David L. Smith is funded by a grant from the Bill and Melinda Gates Foundation (OPP1110495). David L. Smith and Simon I. Hay also acknowledge funding support from the RAPIDD program of the Science and Technology Directorate, Department of Homeland Security, and the Fogarty International Center, National Institutes of Health. J. Kevin Baird is supported by Wellcome Trust grant (B9RJIXO).

Authors' addresses: Rosalind E. Howes, Spatial Ecology and Epidemiology Group, Department of Zoology, University of Oxford, Oxford, United Kingdom, and Center for Global Health and Diseases, Case Western Reserve University, Cleveland, OH, E-mail: rosalind.howes@zoo.ox.ac.uk. Katherine E. Battle, Malaria Atlas Project (MAP), Big Data Institute, Nuffield Department of Medicine, University of Oxford, Oxford, United Kingdom, E-mail: katherine.battle@well.ox.ac.uk. Kamini N. Mendis and Richard E. Cibulskis, Global Malaria Program, World Health Organization, Geneva, Switzerland, E-mails: kaminimendis@gmail.com and cibulskisr@ who.int. David L. Smith, Fogarty International Center, National Institutes of Health, Bethesda, MD, Sanaria Institute for Global Health and Tropical Medicine, Rockville, MD, and Institute for Health Metrics and Evaluation, University of Washington, Seattle, WA, E-mail: smitdave@uw.edu. J. Kevin Baird, Eijkman-Oxford Clinical Research Unit, Jakarta, Indonesia, and Centre for Tropical Medicine, Nuffield Department of Medicine, University of Oxford, Oxford, United Kingdom, E-mail: jkevinbaird@yahoo.com. Simon I. Hay, Fogarty International Center, National Institutes of Health, Bethesda, MD, Institute for Health Metrics and Evaluation, University of Washington, Seattle, WA, and Wellcome Trust Centre for Human Genetics, University of Oxford, Roosevelt Drive, Oxford, United Kingdom, E-mail: sihay@uw.edu.

This is an open-access article distributed under the terms of the Creative Commons Attribution License, which permits unrestricted use, distribution, and reproduction in any medium, provided the original author and source are credited.

The authors are staff members of the World Health Organization. The authors alone are responsible for the views expressed in this article and they do not necessarily represent the decisions, policy or views of the World Health Organization.

\section{REFERENCES}

1. PATH, 2011. Staying the Course? Malaria Research and Development in a Time of Economic Uncertainty. Seattle, WA: PATH.

2. Gething PW, Elyazar IR, Moyes CL, Smith DL, Battle KE, Guerra CA, Patil AP, Tatem AJ, Howes RE, Myers MF, George DB, Horby P, Wertheim HF, Price RN, Mueller I, Baird JK, Hay SI, 2012. A long neglected world malaria map: Plasmodium vivax endemicity in 2010. PLoS Negl Trop Dis 6: e1814.

3. Gething PW, Patil AP, Smith DL, Guerra CA, Elyazar IR, Johnston GL, Tatem AJ, Hay SI, 2011. A new world malaria map: Plasmodium falciparum endemicity in 2010. Malar $J$ 10: 378 .

4. Mueller I, Galinski MR, Tsuboi T, Arevalo-Herrera M, Collins WE, King CL, 2013. Natural acquisition of immunity to Plasmodium vivax: epidemiological observations and potential targets. Adv Parasitol 81: 77-131.

5. Baird JK, 2013. Evidence and implications of mortality associated with acute Plasmodium vivax malaria. Clin Microbiol Rev 26: 36-57. 
6. Baird JK, 2009. Severe and fatal vivax malaria challenges 'benign tertian malaria' dogma. Ann Trop Paediatr 29: 251-252.

7. Price RN, Tjitra E, Guerra CA, Yeung S, White NJ, Anstey NM, 2007. Vivax malaria: neglected and not benign. Am J Trop Med Hyg 77: 79-87.

8. Anstey NM, Douglas NM, Poespoprodjo JR, Price RN, 2012. Plasmodium vivax: clinical spectrum, risk factors and pathogenesis. Adv Parasitol 80: 151-201.

9. Barcus MJ, Basri H, Picarima H, Manyakori C, Sekartuti Elyazar I, Bangs MJ, Maguire JD, Baird JK, 2007. Demographic risk factors for severe and fatal vivax and falciparum malaria among hospital admissions in northeastern Indonesian Papua. Am J Trop Med Hyg 77: 984-991.

10. Bassat Q, Alonso PL, 2011. Defying malaria: fathoming severe Plasmodium vivax disease. Nat Med 17: 48-49.

11. Douglas NM, Anstey NM, Buffet PA, Poespoprodjo JR, Yeo TW, White NJ, Price RN, 2012. The anaemia of Plasmodium vivax malaria. Malar J 11: 135.

12. Genton B, D'Acremont V, Rare L, Baea K, Reeder JC, Alpers MP, Muller I, 2008. Plasmodium vivax and mixed infections are associated with severe malaria in children: a prospective cohort study from Papua New Guinea. PLoS Med 5: e127.

13. Kochar DK, Tanwar GS, Khatri PC, Kochar SK, Sengar GS, Gupta A, Kochar A, Middha S, Acharya J, Saxena V, Pakalapati D, Garg S, Das A, 2010. Clinical features of children hospitalized with malaria-a study from Bikaner, northwest India. Am J Trop Med Hyg 83: 981-989.

14. Lacerda MV, Fragoso SC, Alecrim MG, Alexandre MA, Magalhaes BM, Siqueira AM, Ferreira LC, Araujo JR, Mourao MP, Ferrer M, Castillo P, Martin-Jaular L, FernandezBecerra C, del Portillo H, Ordi J, Alonso PL, Bassat Q, 2012. Postmortem characterization of patients with clinical diagnosis of Plasmodium vivax malaria: to what extent does this parasite kill? Clin Infect Dis 55: e67-e74.

15. Lacerda MV, Mourao MP, Alexandre MA, Siqueira AM, Magalhaes BM, Martinez-Espinosa FE, Filho FS, Brasil P, Ventura AM, Tada MS, Couto VS, Silva AR, Silva RS, Alecrim MG, 2012. Understanding the clinical spectrum of complicated Plasmodium vivax malaria: a systematic review on the contributions of the Brazilian literature. Malar J 11: 12.

16. Lança EFC, Magalhães BML, Vitor-Silva S, Siqueira AM, Benzecry SG, Alexandre MAA, O'Brien C, Bassat Q, Lacerda MVG, 2012. Risk factors and characterization of Plasmodium vivax-associated admissions to pediatric intensive care units in the Brazilian Amazon. PLoS One 7: e35406.

17. Mahgoub H, Gasim GI, Musa IR, Adam I, 2012. Severe Plasmodium vivax malaria among Sudanese children at New Halfa Hospital, eastern Sudan. Parasit Vectors 5: 154.

18. Price RN, Douglas NM, Anstey NM, 2009. New developments in Plasmodium vivax malaria: severe disease and the rise of chloroquine resistance. Curr Opin Infect Dis 22: 430-435.

19. Quispe AM, Pozo E, Guerrero E, Durand S, Baldeviano GC, Edgel KA, Graf PCF, Lescano AG, 2014. Plasmodium vivax hospitalizations in a monoendemic malaria region: severe vivax malaria? Am J Trop Med Hyg 91: 11-17.

20. Tjitra E, Anstey NM, Sugiarto P, Warikar N, Kenangalem E, Karyana M, Lampah DA, Price RN, 2008. Multidrug-resistant Plasmodium vivax associated with severe and fatal malaria: a prospective study in Papua, Indonesia. PLoS Med 5: e128.

21. Baird JK, 2010. Eliminating malaria-all of them. Lancet 376: 1883-1885.

22. Bockarie MJ, Dagoro H, 2006. Are insecticide-treated bednets more protective against Plasmodium falciparum than Plasmodium vivax-infected mosquitoes? Malar J 5: 15.

23. Bousema T, Drakeley C, 2011. Epidemiology and infectivity of Plasmodium falciparum and Plasmodium vivax gametocytes in relation to malaria control and elimination. Clin Microbiol Rev 24: 377-410.

24. Luxemburger C, Perea WA, Delmas G, Pruja C, Pecoul B, Moren A, 1994. Permethrin-impregnated bed nets for the prevention of malaria in schoolchildren on the Thai-Burmese border. Trans $R$ Soc Trop Med Hyg 88: 155-159.

25. Shanks GD, 2012. Control and elimination of Plasmodium vivax. Adv Parasitol 80: 301-341.

26. Tanner M, Greenwood B, Whitty CJ, Ansah EK, Price RN, Dondorp AM, von Seidlein L, Baird JK, Beeson JG, Fowkes
FJ, Hemingway J, Marsh K, Osier F, 2015. Malaria eradication and elimination: views on how to translate a vision into reality. BMC Med 13: 167.

27. Livingstone FB, 1984. The Duffy blood groups, vivax malaria, and malaria selection in human populations: a review. Hum Biol 56: 413-425.

28. Howes RE, Patil AP, Piel FB, Nyangiri OA, Kabaria CW, Gething PW, Zimmerman PA, Barnadas C, Beall CM, Gebremedhin A, Menard D, Williams TN, Weatherall DJ, Hay SI, 2011. The global distribution of the Duffy blood group. Nat Commun 2: 266.

29. Ménard D, Barnadas C, Bouchier C, Henry-Halldin C, Gray LR, Ratsimbasoa A, Thonier V, Carod JF, Domarle O, Colin Y, Bertrand O, Picot J, King CL, Grimberg BT, MercereauPuijalon O, Zimmerman PA, 2010. Plasmodium vivax clinical malaria is commonly observed in Duffy-negative Malagasy people. Proc Natl Acad Sci USA 107: 5967-5971.

30. Zimmerman PA, Ferreira MU, Howes RE, Mercereau-Puijalon O, 2013. Red blood cell polymorphism and susceptibility to Plasmodium vivax. Adv Parasitol 81: 27-76.

31. Guerra CA, Howes RE, Patil AP, Gething PW, Van Boeckel TP, Temperely WH, Kabaria CW, Tatem AJ, Manh BH, Elyazar I, Baird JK, Snow RW, Hay SI, 2010. The international limits and population at risk of Plasmodium vivax transmission in 2009. PLoS Negl Trop Dis 4: e774.

32. Howes RE, Reiner RC Jr, Battle KE, Longbottom J, Mappin B, Ordanovich D, Tatem AJ, Drakeley C, Gething PW, Zimmerman PA, Smith DL, Hay SI, 2015. Plasmodium vivax transmission in Africa. PLoS Negl Trop Dis 9: e0004222.

33. Battle KE, Gething PW, Elyazar IR, Moyes CL, Sinka ME, Howes RE, Guerra CA, Price RN, Baird KJ, Hay SI, 2012. The global public health significance of Plasmodium vivax. Adv Parasitol 80: 1-111.

34. Balk DL, Deichmann U, Yetman G, Pozzi F, Hay SI, Nelson A, 2006. Determining global population distribution: methods, applications and data. Adv Parasitol 62: 119-156.

35. CIESIN/IFPRI/WB/CIAT, 2007. Global Rural Urban Mapping Project (GRUMP) alpha: Gridded Population of the World, Version 2, with Urban Reallocation (GPW-UR). Available at: http:// sedac.ciesin.columbia.edu/gpw. Accessed November 25, 2011.

36. World Health Organization, 2015. World Malaria Report 2015. Geneva, Switzerland: World Health Organization, 280.

37. Mueller I, Zimmerman PA, Reeder JC, 2007. Plasmodium malariae and Plasmodium ovale-the "bashful" malaria parasites. Trends Parasitol 23: 278-283.

38. Moreira CM, Abo-Shehada M, Price RN, Drakeley CJ, 2015. A systematic review of sub-microscopic Plasmodium vivax infection. Malar J 14: 360 .

39. Mueller I, Galinski MR, Baird JK, Carlton JM, Kochar DK, Alonso PL, del Portillo HA, 2009. Key gaps in the knowledge of Plasmodium vivax, a neglected human malaria parasite. Lancet Infect Dis 9: 555-566.

40. da Silva NS, da Silva-Nunes M, Malafronte RS, Menezes MJ, D’Arcadia RR, Komatsu NT, Scopel KK, Braga EM, Cavasini CE, Cordeiro JA, Ferreira MU, 2010. Epidemiology and control of frontier malaria in Brazil: lessons from communitybased studies in rural Amazonia. Trans $R$ Soc Trop Med Hyg 104: 343-350.

41. Harris I, Sharrock WW, Bain LM, Gray KA, Bobogare A, Boaz L, Lilley K, Krause D, Vallely A, Johnson ML, Gatton ML, Shanks GD, Cheng Q, 2010. A large proportion of asymptomatic Plasmodium infections with low and sub-microscopic parasite densities in the low transmission setting of Temotu Province, Solomon Islands: challenges for malaria diagnostics in an elimination setting. Malar J 9: 254.

42. Katsuragawa TH, Gil LH, Tada MS, de Almeida e Silva A, Costa JD, Araujo Mda S, Escobar AL, da Silva LH, 2010. The dynamics of transmission and spatial distribution of malaria in riverside areas of Porto Velho, Rondonia, in the Amazon region of Brazil. PLoS One 5: e9245.

43. Mueller I, Widmer S, Michel D, Maraga S, McNamara DT, Kiniboro B, Sie A, Smith TA, Zimmerman PA, 2009. High sensitivity detection of Plasmodium species reveals positive correlations between infections of different species, shifts in age distribution and reduced local variation in Papua New Guinea. Malar J 8: 41. 
44. Steenkeste N, Rogers WO, Okell L, Jeanne I, Incardona S, Duval L, Chy S, Hewitt S, Chou M, Socheat D, Babin FX, Ariey F, Rogier C, 2010. Sub-microscopic malaria cases and mixed malaria infection in a remote area of high malaria endemicity in Rattanakiri Province, Cambodia: implication for malaria elimination. Malar J 9: 108.

45. Imwong M, Nguyen TN, Tripura R, Peto TJ, Lee SJ, Lwin KM, Suangkanarat P, Jeeyapant A, Vihokhern B, Wongsaen K, Van Hue D, Dong le T, Nguyen TU, Lubell Y, von Seidlein L, Dhorda M, Promnarate C, Snounou G, Malleret B, Renia L, Keereecharoen L, Singhasivanon P, Sirithiranont P, Chalk J, Nguon C, Hien TT, Day N, White NJ, Dondorp A, Nosten F, 2015. The epidemiology of subclinical malaria infections in southeast Asia: findings from cross-sectional surveys in Thailand-Myanmar border areas, Cambodia, and Vietnam. Malar J 14: 381.

46. Cheng Q, Cunningham J, Gatton ML, 2015. Systematic review of sub-microscopic $P$. vivax infections: prevalence and determining factors. PLoS Negl Trop Dis 9: e3413.

47. Waltmann A, Darcy AW, Harris I, Koepfli C, Lodo J, Vahi V, Piziki D, Shanks GD, Barry AE, Whittaker M, Kazura JW, Mueller I, 2015. High rates of asymptomatic, sub-microscopic Plasmodium vivax infection and disappearing Plasmodium falciparum malaria in an area of low transmission in Solomon Islands. PLoS Negl Trop Dis 9: e0003758.

48. Mayxay M, Pukrittayakamee S, Newton PN, White NJ, 2004. Mixed-species malaria infections in humans. Trends Parasitol 20: $233-240$.

49. Douglas NM, Nosten F, Ashley EA, Phaiphun L, van Vugt M, Singhasivanon P, White NJ, Price RN, 2011. Plasmodium vivax recurrence following falciparum and mixed species malaria: risk factors and effect of antimalarial kinetics. Clin Infect Dis 52: 612-620.

50. Machado Siqueira A, Lopes Magalhaes BM, Cardoso Melo G, Ferrer M, Castillo P, Martin-Jaular L, Fernandez-Becerra C, Ordi J, Martinez A, Lacerda MV, del Portillo HA, 2012. Spleen rupture in a case of untreated Plasmodium vivax infection. PLoS Negl Trop Dis 6: e1934.

51. Battle KE, Karhunen MS, Bhatt S, Gething PW, Howes RE, Golding N, Van Boeckel T, Messina JP, Shanks GD, Smith DL, Baird JK, Hay SI, 2014. Geographical variation in Plasmodium vivax relapse. Malar J 13: 144.

52. White NJ, Imwong M, 2012. Relapse. Adv Parasitol 80: 113-150.

53. Baird JK, 2004. Chloroquine resistance in Plasmodium vivax. Antimicrob Agents Chemother 48: 4075-4083.

54. Imwong M, Snounou G, Pukrittayakamee S, Tanomsing N, Kim JR, Nandy A, Guthmann JP, Nosten F, Carlton J, Looareesuwan S, Nair S, Sudimack D, Day NP, Anderson TJ, White NJ, 2007. Relapses of Plasmodium vivax infection usually result from activation of heterologous hypnozoites. J Infect Dis 195: 927-933.

55. Koepfli C, Ross A, Kiniboro B, Smith TA, Zimmerman PA, Siba P, Mueller I, Felger I, 2011. Multiplicity and diversity of Plasmodium vivax infections in a highly endemic region in Papua New Guinea. PLoS Negl Trop Dis 5: e1424.

56. Betuela I, Rosanas-Urgell A, Kiniboro B, Stanisic DI, Samol L, de Lazzari E, del Portillo HA, Siba P, Alonso PL, Bassat Q, Mueller I, 2012. Relapses contribute significantly to the risk of Plasmodium vivax infection and disease in Papua New Guinean children 1-5 years of age. J Infect Dis 206: 1771-1780.

57. Nelwan EJ, Ekawati LL, Tjahjono B, Setiabudy R, Sutanto I, Chand K, Ekasari T, Djoko D, Basri H, Taylor WR, Duparc S, Subekti D, Elyazar I, Noviyanti R, Sudoyo H, Baird JK, 2015. Randomized trial of primaquine hypnozoitocidal efficacy when administered with artemisinin-combined blood schizontocides for radical cure of Plasmodium vivax in Indonesia. BMC Med 13: 294 .

58. Sutanto I, Tjahjono B, Basri H, Taylor WR, Putri FA, Meilia RA, Setiabudy R, Nurleila S, Ekawati LL, Elyazar I, Farrar J, Sudoyo H, Baird JK, 2013. Randomized, open-label trial of primaquine against vivax malaria relapse in Indonesia. Antimicrob Agents Chemother 57: 1128-1135.

59. Coatney GR, Cooper WC, 1948. Recrudescence and relapse in vivax malaria. Proceedings of the 4th International Congress on Tropical Medicine, Vol. 1. Washington, DC: US Government Printing Office, 629-639.
60. Garnham PC, Bray RS, Bruce-Chwatt LJ, Draper CC, KillickKendrick R, Sergiev PG, Tiburskaja NA, Shute PG, Maryon M, 1975. A strain of Plasmodium vivax characterized by prolonged incubation: morphological and biological characteristics. Bull World Health Organ 52: 21-32.

61. Winckel CWF, 1955. Long latency in Plasmodium vivax infections in a temperate zone. Doc Med Geogr Trop 7: 292-298.

62. Coatney GR, Collins WE, Contacos PG, 1971. Plasmodium vivax. The Primate Malarias. Bethesda, MD: U.S. National Institute of Allergy and Infectious Diseases, 43-67.

63. Baird JK, Rieckmann KH, 2003. Can primaquine therapy for vivax malaria be improved? Trends Parasitol 19: 115-120.

64. Shute PG, Lupascu G, Branzei P, Maryon M, Constantinescu P, Bruce-Chwatt LJ, Draper CC, Killick-Kendrick R, Garnham PC, 1976. A strain of Plasmodium vivax characterized by prolonged incubation: the effect of numbers of sporozoites on the length of the prepatent period. Trans $R$ Soc Trop Med Hyg 70: 474-481.

65. White NJ, 2011. Determinants of relapse periodicity in Plasmodium vivax malaria. Malar J 10: 297.

66. Shanks GD, White NJ, 2013. The activation of vivax malaria hypnozoites by infectious diseases. Lancet Infect Dis 13: 900-906.

67. Richie TL, 1988. Interactions between malaria parasites infecting the same vertebrate host. Parasitology 96: 607-639.

68. Hulden L, Hulden L, 2011. Activation of the hypnozoite: a part of Plasmodium vivax life cycle and survival. Malar J 10: 90.

69. Macdonald G, 1957. Local Features of Malaria. The Epidemiology and Control of Malaria. London, United Kingdom: Oxford University Press, 63-99.

70. Howes RE, Battle KE, Satyagraha AW, Baird JK, Hay SI, 2013. G6PD deficiency: global distribution, genetic variants and primaquine therapy. Adv Parasitol 81: 133-201.

71. Cotter C, Sturrock HJ, Hsiang MS, Liu J, Phillips AA, Hwang J, Gueye CS, Fullman N, Gosling RD, Feachem RG, 2013. The changing epidemiology of malaria elimination: new strategies for new challenges. Lancet 382: 900-911.

72. Smith DL, Guerra CA, Snow RW, Hay SI, 2007. Standardizing estimates of the Plasmodium falciparum parasite rate. Malar J 6: 131.

73. Smith T, Hii JL, Genton B, Muller I, Booth M, Gibson N, Narara A, Alpers MP, 2001. Associations of peak shifts in age-prevalence for human malarias with bednet coverage. Trans R Soc Trop Med Hyg 95: 1-6.

74. Senn N, Rarau P, Stanisic DI, Robinson L, Barnadas C, Manong D, Salib M, Iga J, Tarongka N, Ley S, RosanasUrgell A, Aponte JJ, Zimmerman PA, Beeson JG, Schofield L, Siba P, Rogerson SJ, Reeder JC, Mueller I, 2012. Intermittent preventive treatment for malaria in Papua New Guinean infants exposed to Plasmodium falciparum and P. vivax: a randomized controlled trial. PLoS Med 9: e1001195.

75. Michon P, Cole-Tobian JL, Dabod E, Schoepflin S, Igu J, Susapu M, Tarongka N, Zimmerman PA, Reeder JC, Beeson JG, Schofield L, King CL, Mueller I, 2007. The risk of malarial infections and disease in Papua New Guinean children. Am J Trop Med Hyg 76: 997-1008.

76. Poespoprodjo JR, Fobia W, Kenangalem E, Lampah DA, Hasanuddin A, Warikar N, Sugiarto P, Tjitra E, Anstey NM, Price RN, 2009. Vivax malaria: a major cause of morbidity in early infancy. Clin Infect Dis 48: 1704-1712.

77. Koepfli C, Colborn KL, Kiniboro B, Lin E, Speed TP, Siba PM, Felger I, Mueller I, 2013. A high force of Plasmodium vivax blood-stage infection drives the rapid acquisition of immunity in Papua New Guinean children. PLoS Negl Trop Dis 7: e2403.

78. Fowkes FJ, Boeuf P, Beeson JG, 2016. Immunity to malaria in an era of declining malaria transmission. Parasitology 143: $139-153$.

79. Mendis K, Sina BJ, Marchesini P, Carter R, 2001. The neglected burden of Plasmodium vivax malaria. Am J Trop Med Hyg 64: 97-106.

80. Phimpraphi W, Paul RE, Yimsamran S, Puangsa-art S, Thanyavanich N, Maneeboonyang W, Prommongkol S, Sornklom S, Chaimungkun W, Chavez IF, Blanc H, Looareesuwan S, Sakuntabhai A, Singhasivanon P, 2008. Longitudinal study of 
Plasmodium falciparum and Plasmodium vivax in a Karen population in Thailand. Malar J 7: 99.

81. Li N, Parker DM, Yang Z, Fan Q, Zhou G, Ai G, Duan J, Lee MC, Yan G, Matthews SA, Cui L, Wang Y, 2013. Risk factors associated with slide positivity among febrile patients in a conflict zone of north-eastern Myanmar along the ChinaMyanmar border. Malar J 12: 361.

82. Ciuca M, Ballif L, Chelarescu-Viera M, 1934. Immunity in malaria. Trans R Soc Trop Med Hyg 24: 4.

83. Qi Q, Guerra CA, Moyes CL, Elyazar IR, Gething PW, Hay SI, Tatem AJ, 2012. The effects of urbanization on global Plasmodium vivax malaria transmission. Malar J 11: 403.

84. Sinka ME, Bangs MJ, Manguin S, Chareonviriyaphap T, Patil AP, Temperley WH, Gething PW, Elyazar IR, Kabaria CW, Harbach RE, Hay SI, 2011. The dominant Anopheles vectors of human malaria in the Asia-Pacific region: occurrence data, distribution maps and bionomic precis. Parasit Vectors 4: 89.

85. Anvikar AR, Shah N, Dhariwal AC, Sonal GS, Pradhan MM, Ghosh SK, Valecha N, 2016. Epidemiology of Plasmodium vivax malaria in India. Am J Trop Med Hyg 95(Suppl 6): 108-120.

86. Sinka ME, Bangs MJ, Manguin S, Coetzee M, Mbogo CM, Hemingway J, Patil AP, Temperley WH, Gething PW, Kabaria CW, Okara RM, Van Boeckel T, Godfray HC, Harbach RE, Hay SI, 2010. The dominant Anopheles vectors of human malaria in Africa, Europe and the Middle East: occurrence data, distribution maps and bionomic precis. Parasit Vectors 3: 117.

87. Sinka ME, Rubio-Palis Y, Manguin S, Patil AP, Temperley WH, Gething PW, Van Boeckel T, Kabaria CW, Harbach RE, Hay SI, 2010. The dominant Anopheles vectors of human malaria in the Americas: occurrence data, distribution maps and bionomic precis. Parasit Vectors 3: 72 .

88. Killeen GF, 2014. Characterizing, controlling and eliminating residual malaria transmission. Malaria J 13: 330. doi:101186/ 1475-2875-13-330.

89. Nyunt MH, Aye KM, Kyaw MP, Kyaw TT, Hlaing T, Oo K, Zaw NN, Aye TT, San NA, 2014. Challenges in universal coverage and utilization of insecticide-treated bed nets in migrant plantation workers in Myanmar. Malar J 13: 211.

90. World Health Organization and Malaria Consortium, 2011. Workshop to Consolidate Lessons Learned on BCC and Mobile/Migrant Populations in the Strategy to Contain Artemisinin Resistant Malaria. Meeting report, July 5-7, 2011. Luang Prabang, Lao PDR: World Health Organization and Malaria Consortium.

91. Desai M, ter Kuile FO, Nosten F, McGready R, Asamoa K, Brabin B, Newman RD, 2007. Epidemiology and burden of malaria in pregnancy. Lancet Infect Dis 7: 93-104.

92. WHO Evidence Review Group, 2012. Intermittent Preventative Treatment of Malaria in Pregnancy (IPTp) with SulfadoxinePyrimethamine (SP). Meeting report, July 9-11, 2012. Geneva, Switzerland: World Health Organization.

93. Rijken MJ, McGready R, Boel ME, Poespoprodjo R, Singh N, Syafruddin D, Rogerson S, Nosten F, 2012. Malaria in pregnancy in the Asia-Pacific region. Lancet Infect Dis 12: 75-88.

94. Rodriguez-Morales AJ, Sanchez E, Vargas M, Piccolo C, Colina R, Arria M, Franco-Paredes C, 2006. Pregnancy outcomes associated with Plasmodium vivax malaria in northeastern Venezuela. Am J Trop Med Hyg 74: 755-757.

95. Rogerson SJ, Hviid L, Duffy PE, Leke RF, Taylor DW, 2007. Malaria in pregnancy: pathogenesis and immunity. Lancet Infect Dis 7: 105-117.

96. Poespoprodjo JR, Fobia W, Kenangalem E, Lampah DA, Warikar N, Seal A, McGready R, Sugiarto P, Tjitra E, Anstey NM, Price RN, 2008. Adverse pregnancy outcomes in an area where multidrug-resistant Plasmodium vivax and Plasmodium falciparum infections are endemic. Clin Infect Dis 46: 1374-1381.

97. Brabin BJ, Ginny M, Sapau J, Galme K, Paino J, 1990. Consequences of maternal anaemia on outcome of pregnancy in a malaria endemic area in Papua New Guinea. Ann Trop Med Parasitol 84: 11-24.

98. Luxemburger C, Ricci F, Nosten F, Raimond D, Bathet S, White NJ, 1997. The epidemiology of severe malaria in an area of low transmission in Thailand. Trans $R$ Soc Trop Med Hyg 91: 256-262.
99. McGready R, Lee SJ, Wiladphaingern J, Ashley EA, Rijken MJ, Boel M, Simpson JA, Paw MK, Pimanpanarak M, Mu O, Singhasivanon P, White NJ, Nosten FH, 2012. Adverse effects of falciparum and vivax malaria and the safety of antimalarial treatment in early pregnancy: a population-based study. Lancet Infect Dis 12: 388-396.

100. Baird JK, Hoffman SL, 2004. Primaquine therapy for malaria. Clin Infect Dis 39: 1336-1345.

101. Piel FB, Howes RE, Nyangiri OA, Moyes CL, Williams TN, Weatherall DJ, Hay SI, 2013. Online biomedical resources for malaria-related red cell disorders. Hum Mutat 34: 937-944.

102. Kwiatkowski DP, 2005. How malaria has affected the human genome and what human genetics can teach us about malaria. Am J Hum Genet 77: 171-192.

103. Piel FB, Patil AP, Howes RE, Nyangiri OA, Gething PW, Williams TN, Weatherall DJ, Hay SI, 2010. Global distribution of the sickle cell gene and geographical confirmation of the malaria hypothesis. Nat Commun 1: 104.

104. Cattani JA, Gibson FD, Alpers MP, Crane GG, 1987. Hereditary ovalocytosis and reduced susceptibility to malaria in Papua New Guinea. Trans $R$ Soc Trop Med Hyg 81: 705-709.

105. Rosanas-Urgell A, Lin E, Manning L, Rarau P, Laman M, Senn N, Grimberg BT, Tavul L, Stanisic DI, Robinson LJ, Aponte JJ, Dabod E, Reeder JC, Siba P, Zimmerman PA, Davis TM, King CL, Michon P, Mueller I, 2012. Reduced risk of Plasmodium vivax malaria in Papua New Guinean children with southeast Asian ovalocytosis in two cohorts and a case-control study. PLoS Med 9: e1001305.

106. Leslie T, Briceno M, Mayan I, Mohammed N, Klinkenberg E, Sibley CH, Whitty CJ, Rowland M, 2010. The impact of phenotypic and genotypic G6PD deficiency on risk of Plasmodium vivax infection: a case-control study amongst Afghan refugees in Pakistan. PLoS Med 7: e1000283.

107. Louicharoen C, Patin E, Paul R, Nuchprayoon I, Witoonpanich B, Peerapittayamongkol C, Casademont I, Sura T, Laird NM, Singhasivanon P, Quintana-Murci L, Sakuntabhai A, 2009. Positively selected G6PD-Mahidol mutation reduces Plasmodium vivax density in southeast Asians. Science 326: 1546-1549.

108. O'Donnell A, Premawardhena A, Arambepola M, Samaranayake R, Allen SJ, Peto TE, Fisher CA, Cook J, Corran PH, Olivieri NF, Weatherall DJ, 2009. Interaction of malaria with a common form of severe thalassemia in an Asian population. Proc Natl Acad Sci USA 106: 18716-18721.

109. Williams TN, Maitland K, Bennett S, Ganczakowski M, Peto TE, Newbold CI, Bowden DK, Weatherall DJ, Clegg JB, 1996. High incidence of malaria in alpha-thalassaemic children. Nature 383: 522-525.

110. Douglas NM, John GK, von Seidlein L, Anstey NM, Price RN, 2012. Chemotherapeutic strategies for reducing transmission of Plasmodium vivax malaria. Adv Parasitol 80: 271-300.

111. Zimmerman PA, Howes RE, 2015. Malaria diagnosis for malaria elimination. Curr Opin Infect Dis 28: 446-454.

112. Alves FP, Durlacher RR, Menezes MJ, Krieger H, Silva LH, Camargo EP, 2002. High prevalence of asymptomatic Plasmodium vivax and Plasmodium falciparum infections in native Amazonian populations. Am J Trop Med Hyg 66: 641-648.

113. Alves FP, Gil LH, Marrelli MT, Ribolla PE, Camargo EP, Da Silva LH, 2005. Asymptomatic carriers of Plasmodium spp. as infection source for malaria vector mosquitoes in the Brazilian Amazon. J Med Entomol 42: 777-779.

114. Atkinson JA, Johnson ML, Wijesinghe R, Bobogare A, Losi L, O'Sullivan M, Yamaguchi Y, Kenilorea G, Vallely A, Cheng Q, Ebringer A, Bain L, Gray K, Harris I, Whittaker M, Reid H, Clements A, Shanks D, 2012. Operational research to inform a sub-national surveillance intervention for malaria elimination in Solomon Islands. Malar J 11: 101.

115. Coleman RE, Maneechai N, Rachaphaew N, Kumpitak C, Miller RS, Soyseng V, Thimasarn K, Sattabongkot J, 2002. Comparison of field and expert laboratory microscopy for active surveillance for asymptomatic Plasmodium falciparum and Plasmodium vivax in western Thailand. Am J Trop Med Hyg 67: 141-144.

116. Coleman RE, Sattabongkot J, Promstaporm S, Maneechai N, Tippayachai B, Kengluecha A, Rachapaew N, Zollner G, Miller RS, Vaughan JA, Thimasarn K, Khuntirat B, 2006. 
Comparison of PCR and microscopy for the detection of asymptomatic malaria in a Plasmodium falciparum/vivax endemic area in Thailand. Malar J 5: 121.

117. Ganguly S, Saha P, Guha SK, Biswas A, Das S, Kundu PK, Maji AK, 2013. High prevalence of asymptomatic malaria in a tribal population in eastern India. J Clin Microbiol 51: $1439-1444$

118. Herdiana H, Fuad A, Asih PB, Zubaedah S, Arisanti RR, Syafruddin D, Kusnanto H, Sumiwi ME, Yuniarti T, Imran A, Rahmadyani R, Yani M, Kusriastuti R, Tarmizi SN, Laihad FJ, Hawley WA, 2013. Progress towards malaria elimination in Sabang Municipality, Aceh, Indonesia. Malar J 12: 42.

119. Kitvatanachai S, Janyapoon K, Rhongbutsri P, Thap LC, 2003. A survey on malaria in mobile Cambodians in Aranyaprathet, Sa Kaeo Province, Thailand. Southeast Asian J Trop Med Public Health 34: 48-53.

120. Rajendran P, Rajesh PK, Thyagarajan SP, Balakrishnan P, Hari R, Joyee AG, Kurien T, Krishnmurthy P, Jacob V, 2001. Asymptomatic malarial parasitaemia in Tamil Nadu. $J$ Assoc Physicians India 49: 1161-1164.

121. Goonewardena D, 1998. Study of Clinical Immunity to Malaria. Colombo, Sri Lanka: University of Colombo.

122. Doolan DL, Dobano C, Baird JK, 2009. Acquired immunity to malaria. Clin Microbiol Rev 22: 13-36.

123. Barbosa S, Gozze AB, Lima NF, Batista CL, Bastos Mda S, Nicolete VC, Fontoura PS, Goncalves RM, Viana SA, Menezes MJ, Scopel KK, Cavasini CE, Malafronte Rdos S, da SilvaNunes M, Vinetz JM, Castro MC, Ferreira MU, 2014. Epidemiology of disappearing Plasmodium vivax malaria: a case study in rural Amazonia. PLoS Negl Trop Dis 8: e3109.

124. Vallejo AF, Garcia J, Amado-Garavito AB, Arevalo-Herrera M, Herrera S, 2016. Plasmodium vivax gametocyte infectivity in sub-microscopic infections. Malar J 15: 48.

125. White NJ, 2008. The role of anti-malarial drugs in eliminating malaria. Malar J 7 (Suppl 1): S8.

126. McKenzie FE, Wongsrichanalai C, Magill AJ, Forney JR, Permpanich B, Lucas C, Erhart LM, O'Meara WP, Smith DL, Sirichaisinthop J, Gasser RA Jr, 2006. Gametocytemia in Plasmodium vivax and Plasmodium falciparum infections. J Parasitol 92: 1281-1285.

127. Moonen B, Cohen JM, Snow RW, Slutsker L, Drakeley C, Smith DL, Abeyasinghe RR, Rodriguez MH, Maharaj R, Tanner M, Targett G, 2010. Operational strategies to achieve and maintain malaria elimination. Lancet 376: 1592-1603.

128. White MT, Karl S, Battle KE, Hay SI, Mueller I, Ghani AC, 2014. Modelling the contribution of the hypnozoite reservoir to Plasmodium vivax transmission. eLife 3: e04692.

129. Bhatt S, Weiss DJ, Cameron E, Bisanzio D, Mappin B, Dalrymple U, Battle KE, Moyes CL, Henry A, Eckhoff PA, Wenger EA, Briet O, Penny MA, Smith TA, Bennett A, Yukich J, Eisele TP, Griffin JT, Fergus CA, Lynch M, Lindgren F, Murray CJ, Smith DL, Hay SI, Cibulskis RE, Gething PW, 2015. The impact of malaria control on Plasmodium falciparum in Africa, 2000-2015. Nature 526: 207-211.

130. Hay SI, Okiro EA, Gething PW, Patil AP, Tatem AJ, Guerra CA, Snow RW, 2010. Estimating the global clinical burden of Plasmodium falciparum malaria in 2007. PLoS Med 7: e1000290.

131. Cibulskis RE, Aregawi M, Williams R, Otten M, Dye C, 2011. Worldwide incidence of malaria in 2009: estimates, time trends, and a critique of methods. PLoS Med 8: e1001142.

132. World Health Organization, 2014. World Malaria Report 2014. Geneva, Switzerland: World Health Organization, 226.

133. Guerra CA, Hay SI, Lucioparedes LS, Gikandi PW, Tatem AJ, Noor AM, Snow RW, 2007. Assembling a global database of malaria parasite prevalence for the Malaria Atlas Project. Malar J 6: 17.

134. Patil AP, Okiro EA, Gething PW, Guerra CA, Sharma SK, Snow RW, Hay SI, 2009. Defining the relationship between Plasmodium falciparum parasite rate and clinical disease: statistical models for disease burden estimation. Malar J 8: 186

135. Battle KE, Cameron E, Guerra CA, Golding N, Duda KA, Howes RE, Elyazar IRF, Baird JK, Reiner RC Jr, Smith DL, Gething PW, Hay SI, 2015. Defining the relationship between Plasmodium vivax parasite rate and clinical disease. Malar J 14: 191.
136. Cameron E, Battle KE, Bhatt S, Weiss DJ, Bisanzio D, Mappin B, Dalrymple U, Hay SI, Smith DL, Griffin JT, Wenger EA, Eckhoff PA, Smith TA, Penny MA, Gething PW, 2015. Defining the relationship between infection prevalence and clinical incidence of Plasmodium falciparum malaria. Nat Commun 6: 8170.

137. Battle KE, Guerra CA, Golding N, Duda KA, Cameron E, Howes RE, Elyazar IRF, Baird JK, Reiner RC Jr, Smith DL, Gething PW, Hay SI, 2015. Global database of matched Plasmodium falciparum and $P$. vivax incidence and prevalence records from 1985 to 2013. Sci Data 2: 150012.

138. Pampana E, 1969. A Textbook of Malaria Eradication. London, United Kingdom: Oxford University Press.

139. Sattabongkot J, Tsuboi T, Zollner GE, Sirichaisinthop J, Cui L, 2004. Plasmodium vivax transmission: chances for control? Trends Parasitol 20: 192-198.

140. Ministry of Health Sri Lanka and World Health Organization and the University of California-San Francisco, 2012. Eliminating Malaria: Case-study 3. Progress towards Elimination in Sri Lanka. Geneva, Switzerland: World Health Organization.

141. Coura JR, Suarez-Mutis M, Ladeia-Andrade S, 2006. A new challenge for malaria control in Brazil: asymptomatic Plasmodium infection-a review. Mem Inst Oswaldo Cruz 101: 229-237.

142. Povoa MM, Conn JE, Schlichting CD, Amaral JC, Segura MN, Da Silva AN, Dos Santos CC, Lacerda RN, De Souza RT, Galiza D, Santa Rosa EP, Wirtz RA, 2003. Malaria vectors, epidemiology, and the re-emergence of Anopheles darlingi in Belem, Para, Brazil. J Med Entomol 40: 379-386.

143. World Health Organization, 2013. World Malaria Report 2013. Geneva, Switzerland: World Health Organization, 199.

144. Feachem RG, Phillips AA, Hwang J, Cotter C, Wielgosz B, Greenwood BM, Sabot O, Rodriguez MH, Abeyasinghe RR, Ghebreyesus TA, Snow RW, 2010. Shrinking the malaria map: progress and prospects. Lancet 376: 1566-1578.

145. UCSF Global Health Group and Malaria Atlas Project, 2011. Atlas of Malaria-Eliminating Countries. San Francisco, CA: University of California.

146. World Health Organization, 2015. Confronting Plasmodium vivax Malaria. Geneva, Switzerland: World Health Organization, 12 .

147. Baird JK, 2007. Neglect of Plasmodium vivax malaria. Trends Parasitol 23: 533-539.

148. Galinski MR, Barnwell JW, 2008. Plasmodium vivax: who cares? Malar J 7 (Suppl 1): S9.

149. Kochar DK, Saxena V, Singh N, Kochar SK, Kumar SV, Das A, 2005. Plasmodium vivax malaria. Emerg Infect Dis 11: 132-134.

150. World Health Organization, 2012. Management of Severe Malaria: A Practical Handbook, 3rd edition. Geneva, Switzerland: World Health Organization.

151. Kochar DK, Das A, Kochar SK, Saxena V, Sirohi P, Garg S, Kochar A, Khatri MP, Gupta V, 2009. Severe Plasmodium vivax malaria: a report on serial cases from Bikaner in northwestern India. Am J Trop Med Hyg 80: 194-198.

152. Kochar DK, Pakalapati D, Kochar SK, Sirohi P, Khatri MP, Kochar A, Das A, 2007. An unexpected cause of fever and seizures. Lancet 370: 908.

153. Rahimi BA, Thakkinstian A, White NJ, Sirivichayakul C, Dondorp AM, Chokejindachai W, 2014. Severe vivax malaria: a systematic review and meta-analysis of clinical studies since 1900. Malar J 13: 481.

154. Douglas NM, Lampah DA, Kenangalem E, Simpson JA, Poespoprodjo JR, Sugiarto P, Anstey NM, Price RN, 2013. Major burden of severe anemia from non-falciparum malaria species in southern Papua: a hospital-based surveillance study. PLoS Med 10: e1001575; discussion e1001575.

155. Lampah DA, Yeo TW, Malloy M, Kenangalem E, Douglas NM, Ronaldo D, Sugiarto P, Simpson JA, Poespoprodjo JR, Anstey NM, Price RN, 2014. Severe malarial thrombocytopenia: a risk factor for mortality in Papua, Indonesia. J Infect Dis 211: 623-634.

156. Douglas NM, Pontororing GJ, Lampah DA, Yeo TW, Kenangalem E, Poespoprodjo J, Ralph AP, Bangs MJ, Sugiarto P, Anstey NM, Price RN, 2014. Mortality attributable 
to Plasmodium vivax malaria: a clinical audit from Papua, Indonesia. BMC Med 12: 217.

157. Rajahram GS, Barber BE, William T, Grigg MJ, Menon J, Yeo TW, Anstey NM, 2016. Falling Plasmodium knowlesi malaria death rate among adults despite rising incidence, Sabah, Malaysia, 2010-2014. Emerg Infect Dis 22: 41-48.

158. World Health Organization, 2015. Control and Elimination of Plasmodium vivax Malaria: A Technical Brief. Geneva, Switzerland: World Health Organization, 64.

159. Scott JAG, Berkley JA, Mwangi I, Ochola L, Uyoga S, Macharia A, Ndila C, Lowe BS, Mwarumba S, Bauni E, Marsh K, Williams $\mathrm{TN}, 2011$. Relation between falciparum malaria and bacteraemia in Kenyan children: a population-based, case-control study and a longitudinal study. Lancet 378: 1316-1323.

160. Olupot-Olupot P, Urban BC, Jemutai J, Nteziyaremye J, Fanjo HM, Karanja H, Karisa J, Ongodia P, Bwonyo P, Gitau EN, Talbert A, Akech S, Maitland K, 2013. Endotoxaemia is common in children with Plasmodium falciparum malaria. BMC Infect Dis 13: 117.

161. Hochman S, Kim K, 2012. The impact of HIV coinfection on cerebral malaria pathogenesis. J Neuroparasitology 3: 235547.

162. Bhatt S, Gething PW, Brady OJ, Messina JP, Farlow AW, Moyes CL, Drake JM, Brownstein JS, Hoen AG, Sankoh O, Myers MF, George DB, Jaenisch T, Wint GR, Simmons CP, Scott TW, Farrar JJ, Hay SI, 2013. The global distribution and burden of dengue. Nature 496: 504-507.

163. Golding N, Wilson AL, Moyes CL, Cano J, Pigott DM, Velayudhan R, Brooker SJ, Smith DL, Hay SI, Lindsay SW, 2015. Integrating vector control across diseases. BMC Med 13: 249.

164. Mushtaq MB, Qadri MI, Rashid A, 2013. Concurrent infection with dengue and malaria: an unusual presentation. Case Rep Med 2013: 520181.

165. Magalhaes BM, Alexandre MA, Siqueira AM, Melo GC, Gimaque JB, Bastos MS, Figueiredo RM, Carvalho RC, Tavares MA, Naveca FG, Alonso P, Bassat Q, Lacerda MV, Mourao MP, 2012. Clinical profile of concurrent dengue fever and Plasmodium vivax malaria in the Brazilian Amazon: case series of 11 hospitalized patients. Am J Trop Med Hyg 87: $1119-1124$.

166. Deresinski S, 2006. Concurrent Plasmodium vivax malaria and dengue. Emerg Infect Dis 12: 1802.

167. Carme B, Matheus S, Donutil G, Raulin O, Nacher M, Morvan J, 2009. Concurrent dengue and malaria in Cayenne Hospital, French Guiana. Emerg Infect Dis 15: 668-671.

168. Thangaratham PS, Jeevan MK, Rajendran R, Samuel PP, Tyagi BK, 2006. Dual infection by dengue virus and Plasmodium vivax in Alappuzha District, Kerala, India. Jpn J Infect Dis 59: 211-212.

169. GAHI, 2014. Global Atlas of Helminth Infections. Available at: www.thiswormyworld.org. Accessed December 28, 2014.

170. Melo GC, Reyes-Lecca RC, Vitor-Silva S, Monteiro WM, Martins M, Benzecry SG, Alecrim M, Lacerda MV, 2010. Concurrent helminthic infection protects schoolchildren with Plasmodium vivax from anemia. PLoS One 5: e11206.

171. Boel M, Carrara VI, Rijken M, Proux S, Nacher M, Pimanpanarak M, Paw MK, Moo O, Gay H, Bailey W, Singhasivanon P, White NJ, Nosten F, McGready R, 2010. Complex interactions between soil-transmitted helminths and malaria in pregnant women on the Thai-Burmese border. PLoS Negl Trop Dis 4: e887.

172. Williams TN, Maitland K, Phelps L, Bennett S, Peto TE, Viji J, Timothy R, Clegg JB, Weatherall DJ, Bowden DK, 1997. Plasmodium vivax: a cause of malnutrition in young children. QJM 90: 751-757.

173. Baird JK, Valecha N, Duparc S, White NJ, Price RN, 2016. Diagnosis and treatment of Plasmodium vivax malaria. Am J Trop Med Hyg 95(Suppl 6): 35-51.

174. Sumawinata IW, Bernadeta, Leksana B, Sutamihardja A, Purnomo, Subianto B, Sekartuti, Fryauff DJ, Baird JK, 2003. Very high risk of therapeutic failure with chloroquine for uncomplicated Plasmodium falciparum and $P$. vivax malaria in Indonesian Papua. Am J Trop Med Hyg 68: 416-420.

175. Baird JK, Leksana B, Masbar S, Fryauff DJ, Sutanihardja MA, Suradi, Wignall FS, Hoffman SL, 1997. Diagnosis of resistance to chloroquine by Plasmodium vivax: timing of recurrence and whole blood chloroquine levels. Am J Trop Med Hyg 56: 621-626.

176. Asih PB, Syafruddin D, Leake J, Sorontou Y, Sadikin M, Sauerwein RW, Vinetz J, Baird JK, 2011. Phenotyping clinical resistance to chloroquine in Plasmodium vivax in northeastern Papua, Indonesia. Int J Parasitol Drugs Drug Resist 1: 28-32.

177. World Health Organization, 2009. Methods for Surveillance of Antimalarial Drug Efficacy. Geneva, Switzerland: World Health Organization.

178. Rieckmann KH, Davis DR, Hutton DC, 1989. Plasmodium vivax resistance to chloroquine? Lancet 2: 1183-1184.

179. Karunajeewa HA, Mueller I, Senn M, Lin E, Law I, Gomorrai PS, Oa O, Griffin S, Kotab K, Suano P, Tarongka N, Ura A Lautu D, Page-Sharp M, Wong R, Salman S, Siba P, Ilett KF, Davis TM, 2008. A trial of combination antimalarial therapies in children from Papua New Guinea. $N$ Engl J Med 359: 2545-2557.

180. Ratcliff A, Siswantoro H, Kenangalem E, Wuwung M, Brockman A, Edstein MD, Laihad F, Ebsworth EP, Anstey NM, Tjitra E, Price RN, 2007. Therapeutic response of multidrug-resistant Plasmodium falciparum and $P$. vivax to chloroquine and sulfadoxine-pyrimethamine in southern Papua, Indonesia. Trans R Soc Trop Med Hyg 101: 351-359.

181. Sutanto I, Suprijanto S, Nurhayati, Manoempil P, Baird JK, 2009. Resistance to chloroquine by Plasmodium vivax at Alor in the Lesser Sundas Archipelago in eastern Indonesia. Am J Trop Med Hyg 81: 338-342.

182. Price RN, von Seidlein L, Valecha N, Nosten F, Baird JK, White NJ, 2014. Global extent of chloroquine-resistant Plasmodium vivax: a systematic review and meta-analysis. Lancet Infect Dis 14: 982-991.

183. de Santana Filho FS, Arcanjo AR, Chehuan YM, Costa MR, Martinez-Espinosa FE, Vieira JL, Barbosa MG, Alecrim WD, Alecrim MG, 2007. Chloroquine-resistant Plasmodium vivax, Brazilian Amazon. Emerg Infect Dis 13: 1125-1126.

184. Tabernero P, Fernandez FM, Green M, Guerin PJ, Newton PN 2014. Mind the gaps-the epidemiology of poor-quality antimalarials in the malarious world-analysis of the WorldWide Antimalarial Resistance Network database. Malar J 13: 139.

185. Baird JK, 2011. Resistance to chloroquine unhinges vivax malaria therapeutics. Antimicrob Agents Chemother 55: $1827-1830$.

186. Harijanto PN, 2010. Malaria treatment by using artemisinin in Indonesia. Acta Med Indones 42: 51-56.

187. Douglas NM, Anstey NM, Angus BJ, Nosten F, Price RN, 2010. Artemisinin combination therapy for vivax malaria. Lancet Infect Dis 10: 405-416.

188. Ingram RJ, Crenna-Darusallam C, Soebianto S, Noviyanti R, Baird JK, 2014. The clinical and public health problem of relapse despite primaquine therapy: case review of repeated relapses of Plasmodium vivax acquired in Papua New Guinea. Malar J 13: 488.

189. Bennett JW, Pybus BS, Yadava A, Tosh D, Sousa JC, McCarthy WF, Deye G, Melendez V, Ockenhouse CF, 2013. Primaquine failure and cytochrome P-450 2D6 in Plasmodium vivax malaria. N Engl J Med 369: 1381-1382.

190. Bassat Q, Velarde M, Mueller I, Lin J, Leslie T, Wongsrichanalai C, Baird JK, 2016. Key knowledge gaps for Plasmodium vivax control and elimination. Am J Trop Med Hyg 95(Suppl 6): 62-71.

191. Golding N, 2014. ageStand R Package. Available at: https:// github.com/SEEG-Oxford: GitHub. Accessed May 20, 2015.

192. Okell LC, Bousema T, Griffin JT, Ouedraogo AL, Ghani AC, Drakeley CJ, 2012. Factors determining the occurrence of submicroscopic malaria infections and their relevance for control. Nat Commun 3: 1237.

193. White NJ, Pukrittayakamee S, Hien TT, Faiz MA, Mokuolu OA, Dondorp AM, 2013. Malaria. Lancet 383: 723-735. 